
Revue canadienne de chimie

\title{
Prediction of Rate Constants of Important Chemical Reactions in Water Radiation Chemistry in Sub- and Supercritical Water - Non-Equilibrium Reactions
}

\begin{tabular}{|r|l|}
\hline Journal: & Canadian Journal of Chemistry \\
\hline Manuscript ID & cjc-2017-0315.R2 \\
\hline Manuscript Type: & Article \\
\hline Date Submitted by the Author: & 23-Dec-2017 \\
\hline Complete List of Authors: & $\begin{array}{l}\text { Liu, Guangdong; Mount Allison University, Physics } \\
\text { Landry, Cody; Mount Allison University Department of Chemistry and } \\
\text { Biochemistry } \\
\text { Ghandi, Khashayar; Mount Allison University, Physics; Mount Allison } \\
\text { University Department of Chemistry and Biochemistry }\end{array}$ \\
\hline $\begin{array}{r}\text { Is the invited manuscript for } \\
\text { consideration in a Special } \\
\text { Issue?: }\end{array}$ & SFU \\
\hline Keyword: & radiation chemistry, supercritical water, kinetics, Generation IV reactors \\
\hline \multicolumn{2}{|c}{} \\
\hline
\end{tabular}




\section{Prediction of Rate Constants of Important}

2 Chemical Reactions in Water Radiation Chemistry in

\section{Sub- and Supercritical Water - Non-Equilibrium}

\section{Reactions}

5 Guangdong Liu ${ }^{a}$, Cody Landry ${ }^{\mathrm{b}}$, Khashayar Ghandi ${ }^{\mathrm{a}, \mathrm{b} *}$

$6 \quad{ }^{a}$ Department of Physics, Mount Allison University, Sackville, NB E4L 1E2, Canada

7 bepartment of Chemistry and Biochemistry, Mount Allison University, Sackville, NB E4L 1E2,

8 Canada

9 *Corresponding author: Khashayar Ghandi, kghandi@mta.ca, kghandi@triumf.ca 
18 Abstract: The rate constants for reactions involved in the radiolysis of water under relevant

19 thermodynamic conditions in supercritical water-cooled reactors are estimated for inputs in

20 simulations of the radiation chemistry in Generation IV nuclear reactors. We have discussed the

21 mechanism of each chemical reaction with a focus on non-equilibrium reactions. We found most

22 of the reactions are activation-controlled above the critical point and that the rate constants are

23 not significantly pressure-dependent below $300^{\circ} \mathrm{C}$. This work will aid industry with developing

24 chemical control strategies to suppress the concentration of eroding species.

25 Keywords: Generation IV reactors, supercritical water, kinetics, radiation chemistry

\section{1. Introduction}

27 A supercritical water cooled reactor (SCWR) uses supercritical water (SCW) (water above its

28 critical point of $374^{\circ} \mathrm{C}, 221$ bar) as its coolant. ${ }^{1}$ SCWR is one of the proposed Generation IV

29 reactors by the 2002 Nuclear Energy Research Advisory Committee. ${ }^{2}$ SCWRs have

30 advantages, such as increased sustainability, improved safety, and proliferation-resistance. ${ }^{3}$

31 However, the radiolysis (R1) in SCW, which could lead to corrosion, is largely unknown:

$$
\mathrm{R} 1: \mathrm{H}_{2} \mathrm{O} \stackrel{\text { ionizing radiation }}{\longrightarrow} \mathrm{e}_{\mathrm{aq}}^{-}, \mathrm{H} \cdot, \mathrm{OH}, \mathrm{H}_{2}, \mathrm{H}_{2} \mathrm{O}_{2}, \mathrm{HO}_{2}, \mathrm{O}_{2}^{-} \text {. }
$$

33 Chemical control strategies are used to mitigate corrosion in nuclear reactors. ${ }^{4}$ In existing

34 nuclear reactors, chemicals such as hydrogen are added to the coolant to chemically react with

35 and suppress the concentration of oxidizing species. ${ }^{4}$ In SCWRs, the type of chemicals to add,

36 and the amount to add, if any, are unknown, and are hard to determine experimentally.

37 Computer simulations such as Monte Carlo simulations, ${ }^{5,6}$ can be used to find the optimum

38 coolant composition that minimizes the production of corrosive radiolysis products. ${ }^{7}$ 
In 2009, Atomic Energy of Canada Limited (AECL) published a review of the rate constants for

40 radiolysis of water at temperatures below SCWR conditions. ${ }^{8}$ Although the rate constants of

41 reactions in water mostly follow Arrhenius temperature dependence at low temperatures,

42 several studies have shown that the rate constants of many reactions in water plateau and may

43 even decrease near the critical point. ${ }^{9-16}$ Accurate predictions of rate constants of relevant

44 reactions in SCW are crucial for the development of chemical control strategies to minimize

45 corrosion in SCWRs. ${ }^{7,17}$ The goal of this work is to give recommendations for the rate constants

46 of important reactions in radiolysis of water under hydrothermal conditions based on a model

47 proposed by Ghandi et al. ${ }^{11}$ that accounts for the non-Arrhenius temperature dependence of

48 different reactions in water. Table S1 in the Supporting Information (SI) contains all reactions.

49 The labeling of reactions are adapted from AECL report. ${ }^{8}$ We have previously addressed all the

50 significant equilibrium reactions involved in the radiation chemistry of water (Reactions R23-

51 R32) under SCWRs coolant's thermodynamic conditions. ${ }^{7}$ This paper addressed the non-

52 equilibrium reactions (Reactions R2-R22a) which are grouped according to their mechanisms in

53 Table 1. The methodology was described in detail previously ${ }^{13}$ and in the SI. ${ }^{7}$

54 Although all reactions that are discussed in this paper (R2-R22a) are important in the

55 radiolysis of water, in order to make the main text of this paper as concise as possible we had to

56 transfer discussion of many reactions to the SI. The splitting of the reactions that are discussed

57 in the main text vs. those in SI is mainly done based on g-values. The g-value is defined as the

58 number of species formed or dissociated per $100 \mathrm{eV}$ energy absorbed. Some species in water

59 such as $\cdot \mathrm{OH}, \mathrm{e}_{\mathrm{aq}}{ }^{-}, \mathrm{H} \cdot$ and $\mathrm{H}_{2}$ have larger g-values at around $350^{\circ} \mathrm{C},{ }^{8}$ and are expected to be

60 important in SCW as discussed in section 2.6. Thus, their reactions should be given more

61 attention as they can significantly change the outcome of Monte Carlo simulations. ${ }^{7}$ As such,

62 we discussed these reactions ( $R 3, R 4, R 5, R 6, R 7)$, and the reactions that require special 
63 treatments to model in the main text (R2, R15), while discussion of the other reactions are

64 provided in the SI. Despite this splitting of reactions, we strongly recommend that the readers

65 also carefully study all reactions we discussed in the SI. The readers who model the radiation

66 chemistry in coolants of SCWR should know that the tables of all reaction rate constants and

67 activation parameters are reported in the SI. A brief summary of all reactions involved (including

68 the equilibrium reactions) is provided at the end of the main text. Since we both describe and

69 classify the reactions based on their mechanisms, the reactions are not discussed in numerical

70 order (e.g. R4 is discussed before R3 and R2, etc.)

\section{2. Results and Discussion}

\subsection{The cage effect}

73 A model that considers the number of collisions during the lifetime of an encounter pair is used

74 in this work to account for the observed significant decrease of rate constants of reactions in

75 water at high temperatures. ${ }^{7,11}$ The process in which reactant species diffuse together to

76 become neighbors is called an encounter. In order for a reaction to occur, diffusion of the

77 reactants into the same water cage is required. The solvent cage will keep the reactants in close

78 proximity for a while, during which they will collide with each other and with the water molecules

79 surrounding them. The lifetime of an encounter is the time that the reactants remain within the

80 same water cage. The temperature dependence of the encounter time at a certain pressure is

81 discussed when introducing the first reaction we investigated.

82 For a reaction to occur, the reactants must be oriented properly to allow new bonds to form.

83 Once the reactants enter the same water cage, they will collide with each other, reorient, and 
85 reaction to occur, or they will escape from the cage. When temperature increases, the hydrogen

86 bond ( $\mathrm{H}$ bond) length also increases and thus $\mathrm{H}$ bond becomes weaker. ${ }^{18} \mathrm{As}$ a result, the

87 energy barrier to escape a cage formed by these bonds decreases. This has two implications,

88 the first being reactants moving from cage to cage faster (larger diffusion coefficients) and the

89 second being that reactants, once in the same cage, have a shorter encounter lifetime to

90 accommodate proper orientation for reaction. As a result, the probability that the reactants will

91 find the right orientation to react decreases, and therefore the efficiency of the reaction is

92 reduced. ${ }^{7,11}$ This is accounted for in our model by including an efficiency factor, $f_{\mathrm{R}}$, which is

93 proportional to the number of collisions per encounter. This is described further when discussing

94 Reaction R4 and in the SI.

\subsection{Addition / Non-dissociative attachment}

96 As will be described in section 2.3, Reaction R2 is heavily influenced by Coulomb interactions.

97 Reaction R3 is only influenced by spin orientation not the orientation of reactants. On the other

98 hand, in reaction $\mathrm{R} 4\left(\cdot \mathrm{OH}+\cdot \mathrm{OH} \rightarrow \mathrm{H}_{2} \mathrm{O}_{2}\right)$, the $\cdot \mathrm{OH}$ radicals must approach each other in an

99 orientation that allows new bonds to be formed between the $\mathrm{O}$ atoms, hence influenced by the

100 cage effect more than $\mathrm{H} \cdot$ atom reactions. Thence we introduced this reaction first, and used it as 101 an example to show the timescales and collisions per encounter and in general the cage effect.

102 R4:

$$
\cdot \mathrm{OH}+\cdot \mathrm{OH} \rightarrow \mathrm{H}_{2} \mathrm{O}_{2}
$$

103 The self-recombination of hydroxyl radicals produces hydrogen peroxide, which can

104 decompose into molecular oxygen and water. This reaction is important in SCWRs, as the crack

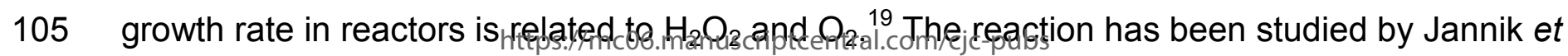


106 al. ${ }^{20}$ from 150 to $350^{\circ} \mathrm{C}$ at 250 bar, by directly measuring $\cdot \mathrm{OH}$ radical transient optical absorption

107 at $250 \mathrm{~nm}$. They suggested the use of the Noyes equation to describe the non-Arrhenius

108 behavior. In their system, hydrogen radicals reached up to $30 \%$ of the total yield of hydroxyl

109 radicals at $350^{\circ} \mathrm{C}$. Due to the ambiguity of the extinction coefficient at higher temperatures, the

110 actual rate will differ from the measured one in the high-temperature range.$^{20}$ Elliot et al..$^{21}$

111 studied the same reaction from 20 to $200^{\circ} \mathrm{C}$. Both studies are done using $\mathrm{N}_{2} \mathrm{O}$ saturated solution

112 because solvated electrons react with $\mathrm{N}_{2} \mathrm{O}$ and convert them to $\cdot \mathrm{OH}$ radicals.

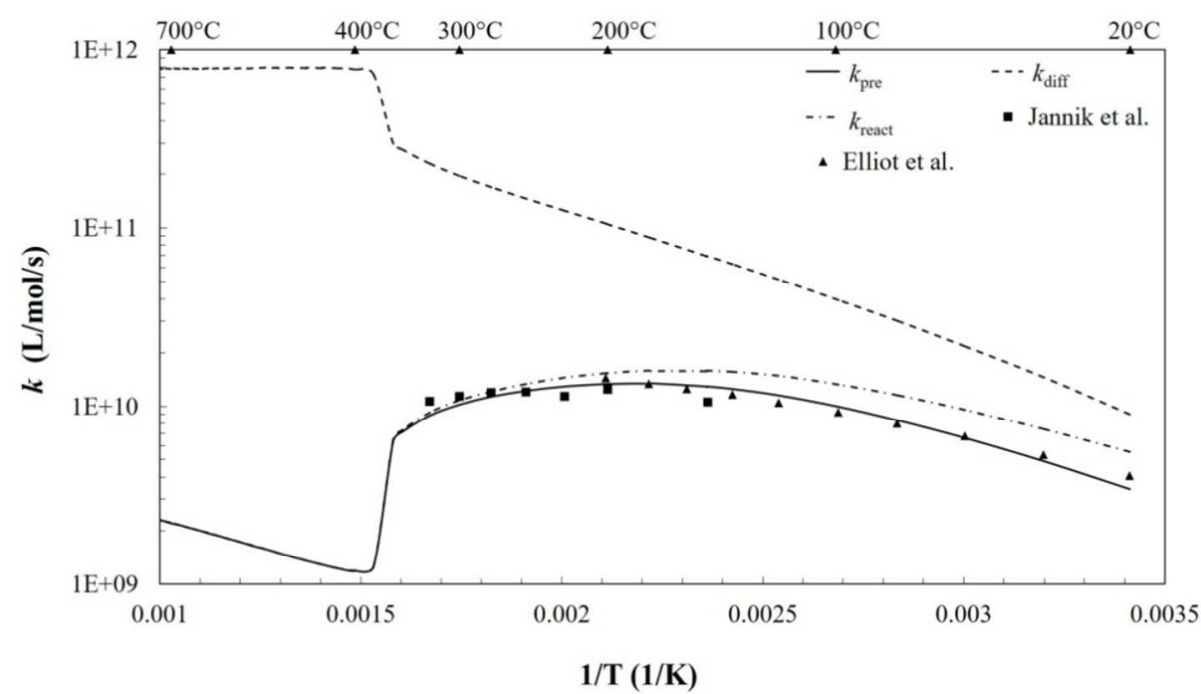

113 Figure 1 The Arrhenius plot of the data from Jannik et al. ${ }^{20}$ and Elliot et al. ${ }^{21}$, with our fit of $k_{\text {pre }}$

114 to the data and extrapolations to high temperatures for $\mathrm{R} 4: \cdot \mathrm{OH}+\cdot \mathrm{OH} \rightarrow \mathrm{H}_{2} \mathrm{O}_{2}$ at 250 bar.

115 Elliot found an activation energy of $3.7 \mathrm{~kJ} \mathrm{~mol}^{-1}$ which is smaller than our fit value $12 \mathrm{~kJ} \mathrm{~mol}^{-1}$.

116 This reaction is not a diffusion-controlled reaction, as can be seen from our fits. It is strongly

117 influenced by the cage effect as can be seen by the rapid drop in reaction rate near the critical

118 point in Figure 1. This is the reason for the difference in our activation energy and the one

119 reported by Elliot et al. ${ }^{21}$ Figure 1 suggests that although there are enough encounters for the

120 reaction, the efficiency of the reaction at high temperatures is low due to the cage effect (the

$121 \mathrm{OH}$ radicals are not able to find the right orientation to react before leaving the water cage). 
122 Therefore, the $f_{\mathrm{R}}$ factor will be a small number at high temperatures. To estimate the duration of

123 encounter $\tau_{\mathrm{enc}}$, we assumed the encounter pairs are in equilibrium with the separated reactants.

124 The equilibrium constant can be written as the ratio of the diffusion rate constant and the

125 separation rate of the reactants: $K_{\text {enc }}=k_{\text {diff }} / \tau_{\text {enc }}{ }^{-1} \cdot{ }^{11} K_{\text {enc }}$ can be estimated by considering the 126 probability of finding one reactant as next nearest neighbor to the other. Using a coordination

127 number of 8 , we found $K_{\text {enc }}=8 /\left[\mathrm{H}_{2} \mathrm{O}\right]$. Then, $\tau_{\text {enc }}$ can be calculated using the formula: ${ }^{11}$

$$
\mathbf{G}_{e n c}=\frac{8}{k_{\mathrm{diff} \times\left[\mathrm{H}_{2} \mathrm{O}\right]}}
$$

129 The duration of collision $\tau_{\text {coll }}$ can be estimated based on collision time in gas-phase, collision 130 frequency, scaled with the inverse self-diffusion constant of the solvent: ${ }^{11}$

$$
\mathrm{t}_{\text {coll }}=Z^{-1}(\rho)=Z_{0}^{-1} D(\rho) / D\left(\rho_{0}\right)
$$

132 where $\rho$ is density, $Z_{0}^{-1}$ is scaling constant, $D(\rho)$ is self-diffusion constant of water at a given 133 temperature, and $D\left(\rho_{0}\right)$ is self-diffusion of water at reference state which is chosen to be $450^{\circ} \mathrm{C}$ 134 and 240 bar consistent with previous work. ${ }^{11}$ The $\tau_{\text {coll }} / \tau_{\text {enc }}$ gives the number of collisions per 135 encounter (Figure 2). There are around 1000 collisions per encounter for this reaction at lowest 136 temperature. Other reactions have an order of $10^{2}$ to $10^{3}$ collisions per encounter at room 137 temperature. In SCW, the weak $\mathrm{H}$ bonds do not hold water molecules together for more than 1 138 ps as opposed $\sim 31$ ps at room temperature, ${ }^{18,22}$ and the number of $\mathrm{H}$ bonds per water molecule 139 decreases as temperature is increased at a given pressure. ${ }^{23}$ As temperature increases to near 140 the critical point, collisions per encounter decrease and the value of $f_{\mathrm{R}}$ also decreases. ${ }^{7}$ 
141 The temperature dependence of $f_{R}$ and collisions per encounter are similar (Figure 2). At room

142 temperature $f_{\mathrm{R}}$ is around 1 and as temperature increase to near the critical point, it decreases to

143 about 0.001 to $0.01 .{ }^{7}$ Above the critical point, at high enough temperatures there is one collision

144 per encounter, thus $f_{\mathrm{R}}$ remains constant.

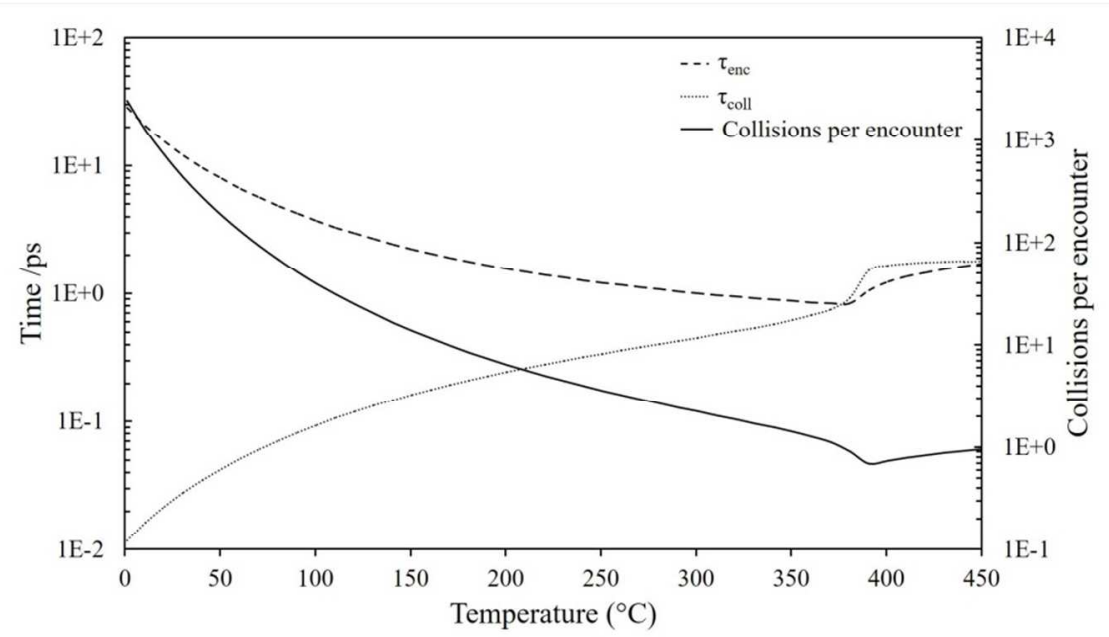

145 Figure $2 \tau_{\text {enc }}$ and $\tau_{\text {coll }}\left(y\right.$-axis on the left), and collisions per encounter $\left(\tau_{\text {coll }} / \tau_{\text {enc }}, y\right.$-axis on the 146 right) for $\mathrm{R} 4$.

147 Including $f_{\mathrm{R}}$ in Arrhenius equation, the temperature dependence will be like Figure 1. It goes

148 through a maximum before the critical point, before increasing via an Arrhenius temperature

149 dependence. The rate constants of most reactions studied in this work follow a similar

150 temperature dependence thus their details are only reported in the SI.

$151 \quad$ R3:

$$
\mathrm{H} \cdot+\mathrm{H} \cdot \rightarrow \mathrm{H}_{2}
$$

152 The recombination of $\mathrm{H} \cdot$ atoms between 20 and $250^{\circ} \mathrm{C}$ at 140 bar was measured by Sehested

153 et al., ${ }^{24}$, by observing the UV spectrum of the $\mathrm{H} \cdot$ atom at $\mathrm{pH}$ 2. Their rate constants are lower

154 limits of the real values at higher temperatures because the extinction coefficient was assumed 
155 to be temperature independent, but it increases by $10 \%$ from 20 to $200^{\circ} \mathrm{C}^{24}$ They obtained an 156 activation energy of $14.7 \mathrm{~kJ} \mathrm{~mol}^{-1}$; the activation energy from our fit is $7.8 \mathrm{~kJ} \mathrm{~mol}^{-1}$.

157 Sehested and Christensen did not account for the spin exchange ${ }^{11}$. The addition reaction, 158 however, is in competition with the spin exchange. Electron spin exchange is common in low 159 energy collisions between species with unpaired electron. ${ }^{25}$ For example, a collision between 160 two $\mathrm{H} \cdot$ atoms of spin states $\left|\alpha_{p} \alpha_{e}\right\rangle$ and $\left|\beta_{p} \beta_{e}\right\rangle$ ( $\alpha$ is spin up, $\beta$ is spin down, $\mathrm{p}$ denotes the proton, 161 and e denotes the electron), will result in $\left|\alpha_{p} \beta_{e}\right\rangle$ and $\left|\beta_{p} \alpha_{e}\right\rangle$, if spin exchange occurs. Similar to 162 the collisions per encounter of hydroxyl radicals in Figure 2, there are more collisions during an 163 encounter of two hydrogen atoms of opposite electron spins at low temperatures (the reaction 164 happens only if the electron spins are opposite). At each collision, a spin exchange or an 165 addition reaction can occur. Although spin exchange will not prevent an addition reaction, an 166 addition reaction will prevent a spin exchange. If there are more collisions in an encounter, an 167 addition reaction will eventually occur. Thus, it is reasonable to assume this reaction is diffusion168 controlled at low temperatures. At high temperatures, there is essentially only one collision 169 during an encounter. Therefore, the probability of the $\mathrm{H} \cdot$ atoms going through an addition 170 reaction is significantly smaller at higher temperatures.

171 For spin exchange, the rate constant depends on the number of encounters, $k_{\text {diff; }}$ the 172 exchange factor, $p_{\text {spin }}$, and the strength of the exchange interaction, $J^{11}$ :

$$
k_{\text {pre }}=p_{\text {spin }} k_{\text {diff }} f_{\mathrm{J}} ; \quad f_{\mathrm{J}}=J^{2} \tau_{\text {enc }}^{2} /\left(1+J^{2} \tau_{\text {enc }}^{2}\right)
$$

174 where $\tau_{e n c}$ is the duration of the encounter, $k_{\text {diff }}$ is the diffusion rate constant. For a strong spin 175 exchange limit, $k_{\text {pre }}$ only depends on $p_{\text {spin. }}$ For weak a spin exchange, $f_{\mathrm{J}}$ shows a similar 
176 temperature dependent trend as $f_{\mathrm{R}}$ factor, although instead of orientation, $f_{\mathrm{J}}$ only depends on the

177 number of collisions in an encounter. ${ }^{11}$

178 For this reaction, orientation is not an important factor considering the electronic aspects; only

179 the spin orientation is important. Also since $\mathrm{H}$-atom reactions could be affected by quantum

180 tunneling at low temperatures, this reaction could be diffusion-controlled in this range. Hence,

181 the possibility of contribution from a diffusion-controlled mechanism at high temperatures cannot

182 be discounted. We have already shown in our previous work that the Stoke-Einstein diffusion

183 model underestimates diffusion coefficients above the critical point. ${ }^{7}$ As such, we used a scaled

184 diffusion model of water by Kallikragas et al. ${ }^{26}$ at high temperatures, and the Stoke-Einstein

185 diffusion model at low temperatures up to $250^{\circ} \mathrm{C}$ and matched the value of these two curves at

$186250^{\circ} \mathrm{C}$, because at this point we still know the rate constant from the experiment data (Figure 3).

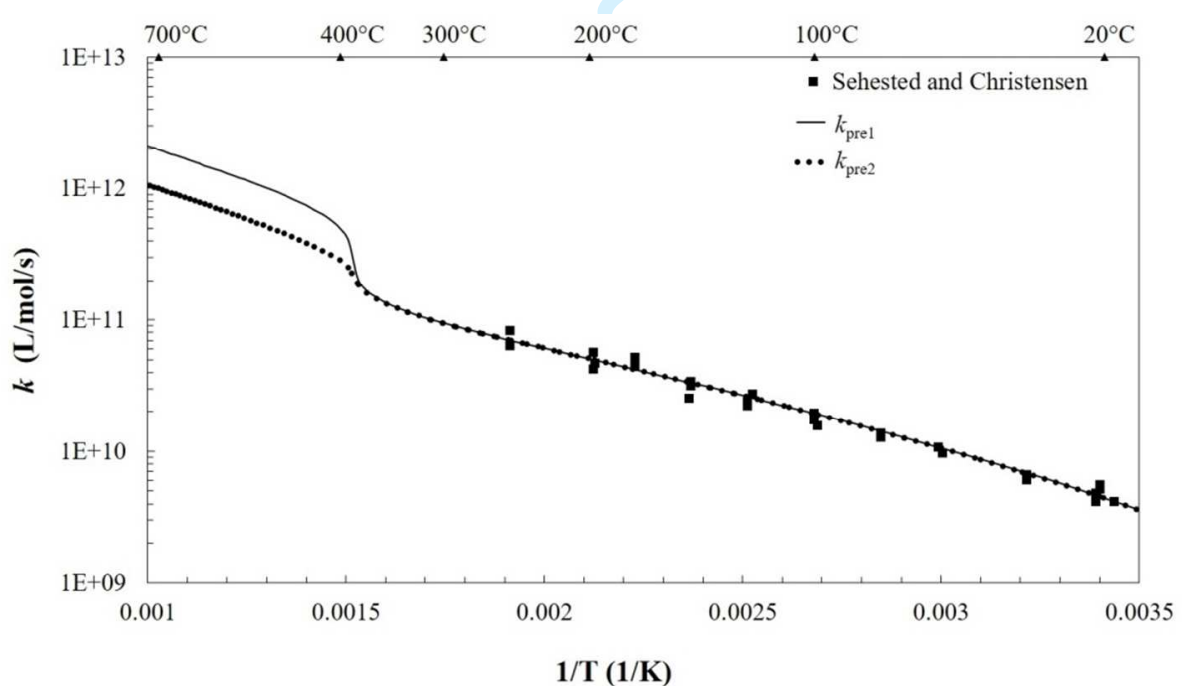

187 Figure 3 The experimental data from Sehested and Christensen ${ }^{24}$, along with our fit of $k_{\text {pre } 1}$ to

188 the experimental data and its extrapolation to high temperatures for R3. We assumed a

189 diffusion-controlled reaction for R3. For $k_{\text {pre2 }}$, we took into consideration the competition with

190 spin exchange as described in the text. 
191 We can correct the rate constants to account for the statistical factor (addition vs. spin 192 exchange) if in each collision the probability of an addition reaction is $p_{\text {coll. }}$. We can estimate the 193 number of collisions, $n_{\text {coll }}$, in an encounter at different temperatures using the $f_{\mathrm{R}}$ factor, assuming 194 only one collision per encounter at very high temperature. The probability that an addition 195 reaction occurs in an encounter is calculated as:

$$
p_{\text {add }}=1-\left(1-p_{\text {coll }}\right)^{n_{\text {coll }}}
$$

Multiplying this probability by the diffusion rate constants, and assuming $p_{\text {coll }}$ is 0.5 , we obtain

$198 k_{\text {pre2 }}$ in Figure 3 . The $p_{\text {coll }}$ is chosen to be 0.5 , but the real value could be slightly smaller. We 199 report the rate constants in the SI for both the diffusion-controlled model, and the diffusion200 controlled model in which we accounted for the competition between addition and spin 201 exchange. We recommend the latter.

202 R6:

$$
\mathrm{e}_{\mathrm{aq}}^{-}+\cdot \mathrm{OH} \rightarrow \mathrm{OH}^{-}
$$

203 The reaction between a hydrated electron and hydroxyl radical is important: it changes the $\mathrm{pH}$ 204 of the solution in the radiolysis track and turns $\cdot \mathrm{OH}$ radicals into less reactive $\mathrm{OH}^{-}$ions. $\mathrm{pH}$ is a 205 critical factor for corrosion control in water-cooled nuclear reactors, since it is a significant 206 parameter that affects the speciation and solubility of metal oxide and hydroxides (corrosion 207 passivation layers). ${ }^{27}$ A recent Monte Carlo study by Kanike et al. ${ }^{28}$ shows that a spur formed in 208 the radiolysis of room temperature water is acidic in the early stage, and becomes neutral with 209 time. The increase in $\mathrm{pH}$ is mainly due to two reactions: $\mathrm{H}_{3} \mathrm{O}^{+}$reacting with $\mathrm{OH}^{-}$, and $\mathrm{H}_{3} \mathrm{O}^{+}$ 210 reacting with $\mathrm{e}_{\mathrm{aq}} \cdot{ }^{-28} \mathrm{R} 6$ plays an important role here, as it is linked to the two species. This 
211 shows that it is important to have accurate rate constants in order to model water radiolysis

212 since the population of all species are related by different reactions.

213 R6 has been studied by Christensen et al. ${ }^{29}$, Elliot et al. ${ }^{30}$, and Janik and Bartels. ${ }^{8}$

214 Christensen et al. ${ }^{29}$ studied it with pulse radiolysis at a pH of 10.0 to 10.6 using a buffer, and

215 Elliot et al. ${ }^{30}$ studied this reaction using a deoxygenated borate-buffered solution of $\mathrm{pH}$ 9.2. All

216 rate constants were obtained by observing the decay of hydrated electrons in either a buffer or

217 in alkaline water. There is a reasonable agreement between the work of Elliot et al. ${ }^{30}$ and Janik

218 and Bartels ${ }^{8}$, while data from Christenson et al. ${ }^{29}$ suggests higher rate constants. Our fit shows

219 that R6 is an activation-controlled reaction at high temperatures with a small activation energy of

$2204 \mathrm{~kJ} \mathrm{~mol}^{-1}$, and a diffusion-controlled reaction up to $\sim 200^{\circ} \mathrm{C}$ (Figure 4). This reaction is a

221 diffusion-controlled reaction at room temperature, and the $k_{\text {diff }}$ for this reaction is larger than R3

222 at this temperature. This is likely due to the hydrated electron having a faster diffusion rate than

$223 \mathrm{H} \cdot$, and also the $\cdot \mathrm{OH}$ radical has a larger reaction radius than $\mathrm{H} \cdot{ }^{21}$

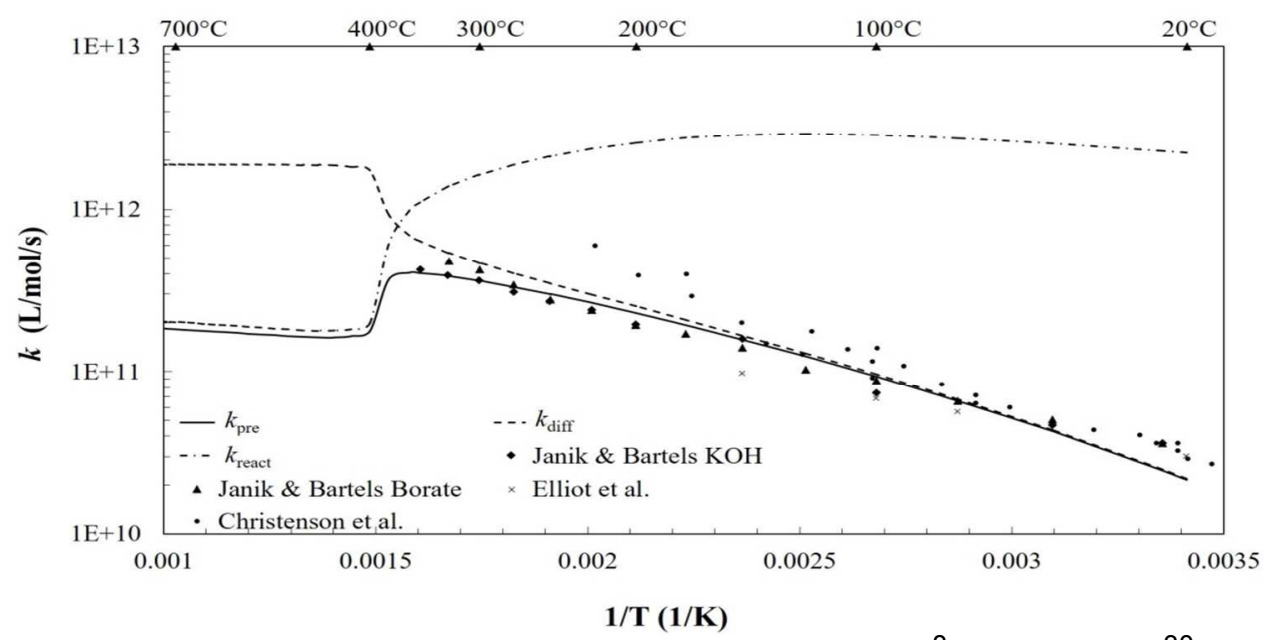

224 Figure 4 The experimental data from Janik and Bartels ${ }^{8}$, Elliot et al. ${ }^{30}$, and Christenson et al. ${ }^{29}$,

225 along with our fit of $k_{\text {pre }}$ to the experimental data and its extrapolation to high temperatures for

$226 \mathrm{R} 6: \mathrm{e}_{\mathrm{aq}}{ }^{-}+\cdot \mathrm{OH} \rightarrow \mathrm{OH}^{-}$. A pressure of 250 bar is used in this figure. 
$227 \quad$ R7:

$$
\mathrm{H} \cdot+\cdot \mathrm{OH} \rightarrow \mathrm{H}_{2} \mathrm{O}
$$

228 This reaction has been studied by Lundstrom et al. ${ }^{31}$ and Buxton and Elliot. ${ }^{32}$ Lundstrom et 229 al. ${ }^{31}$ studied this reaction at 100 bar between 5 and $233^{\circ} \mathrm{C}$ at $\mathrm{pH}=2$ (Figure 5). They reported 230 an activation energy of $8.2 \pm 0.4 \mathrm{~kJ} / \mathrm{mol}^{31}$ close to our activation energy, $11 \mathrm{~kJ} \mathrm{~mol}^{-1}$.

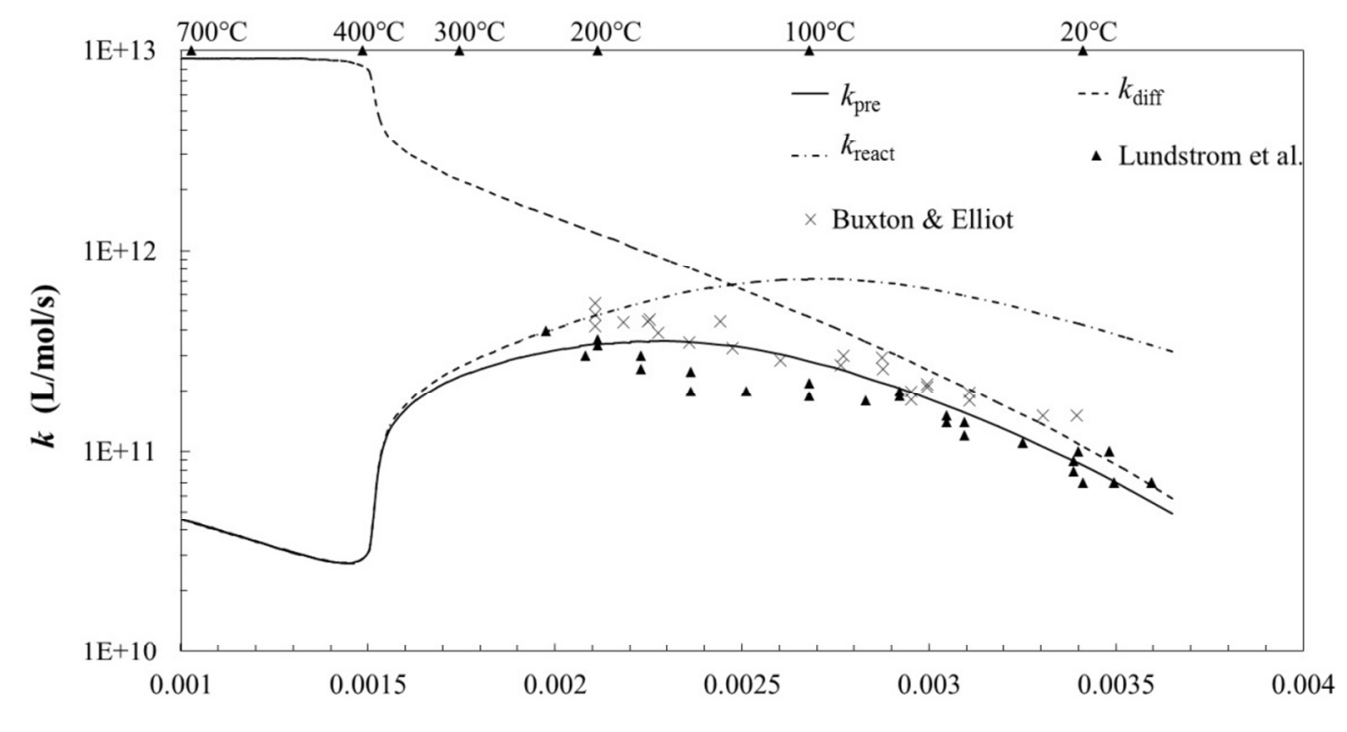

$1 / \mathrm{T}(\mathbf{1} / \mathrm{K})$

232 Figure 5 The experimental data from Lundstrom et al. ${ }^{31}$ and Buxton \& Elliot ${ }^{32}$, along with our fit

233 of $k_{\text {pre }}$ to the experimental data and its extrapolation to high temperatures for the reaction R7: $\mathrm{H}$.

$234+\cdot \mathrm{OH} \rightarrow \mathrm{H}_{2} \mathrm{O}$. A pressure of 250 bar was used.

235 Buxton and Elliot ${ }^{32}$ studied $\mathrm{R} 7$ up to $200^{\circ} \mathrm{C}$ using pulse radiolysis of $10^{-2} \mathrm{~mol} \mathrm{dm}^{-3} \mathrm{HCLO}_{4}$ 236 solution. The extinction coefficient was assumed to be independent of temperature in both 237 papers, but it is believed that the extinction coefficient does change with temperature. ${ }^{8}$ Buxton 238 compares this reaction with two other reactions ( $R 3$ and $R 4$ ) and finds that $R 7$ is closer to $R 4$ 239 than R3; therefore, they qualitatively conclude it is not a diffusion-controlled reaction. However, 
241 Although the diffusion rate of $\mathrm{H} \cdot$ is higher than that of the $\cdot \mathrm{OH}$ radical, the reaction radius of $\cdot \mathrm{OH}$

242 is larger than the reaction radius of the $\mathrm{H} \cdot$ atom at room temperature. ${ }^{21,33}$ This is likely the

243 reason that the $k_{\text {diff }}$ of R7 and R4 are higher than R3 at low temperatures. Our predictions show

244 a peak rate constant at around $180^{\circ} \mathrm{C}$. The rate constant then rapidly drops until about $352^{\circ} \mathrm{C}$.

\section{$245 \quad$ R15:}

$$
\mathrm{H} \cdot+\mathrm{O}_{2}^{-} \rightarrow \mathrm{HO}_{2}^{-}
$$

246 Experimental rate constants do not exist for this reaction. Thus, we did quantum calculations for

247 the gas phase at room temperature with Gaussian $09^{34}$ using a density function theory (DFT) $)^{35}$

248 with the B3LYP functional ${ }^{36,37}$ (UB3LYP) and a basis set of $6-311++G(d, p)^{38}$. The transition

249 state is calculated using the STQN method. ${ }^{39}$ The frequency calculation is performed at the

250 same level to confirm that the structure found in the calculation is a transition state (i.e. with a

251 single imaginary frequency) and to study the thermal effects on activation parameters. From the

252 frequency calculation, the activation entropy $\left(\Delta \mathrm{S}^{\ddagger}\right)$ and enthalpy $\left(\Delta \mathrm{H}^{\ddagger}\right)$ can be obtained. The gas

253 phase activation energy $\left(E_{\mathrm{a}}\right)$ and the pre-exponential factor $(A)$ can be calculated using the

254 formula [5] and [6]: ${ }^{19,40}$

$$
E_{\mathrm{a}}=\Delta H^{\ddagger}+2 R T
$$

$$
\log _{10}(A)=\log _{10}\left(\frac{e^{2} k_{B} T}{h c_{o}}\right)+\left(\frac{\Delta S^{\ddagger}}{2.303 R}\right)
$$

257 where $R$ is the gas constant, $k_{\mathrm{B}}$ is the Boltzmann constant, $T$ is the temperature, $e$ is the Euler's 258 number, $h$ is the Planck constant, $c_{o}$ is the concentration of water. From these calculations, we 259 obtained an activation energy of $42 \mathrm{~kJ} \mathrm{~mol}^{-1}$, and a pre-exponential factor of $6.0 \times 10^{11} \mathrm{dm}^{3} \mathrm{~mol}^{-1}$ 
261 error of around $16 \mathrm{~kJ} \mathrm{~mol}{ }^{-1}$ for activation enthalpy. ${ }^{41}$ The basis set we used is likely to yield a 262 more precise result since it uses more functions to describe the valence electrons and has more 263 flexibilities when describing molecular orbitals. ${ }^{38}$ It is assumed that the $B(r)$ and $p_{\mathrm{R}} k_{\text {gas }}$ (fitting 264 parameters used in this work, described in SI) of R15 are the same as those of R13, as the 265 reactants of R13 are similar to R15, but without charges. The mechanism of this reaction is a 266 hydrogen atom approaching the oxygen pair from an angle of around 55 degrees from the O-O 267 bond. The rate constant of this reaction is shown in

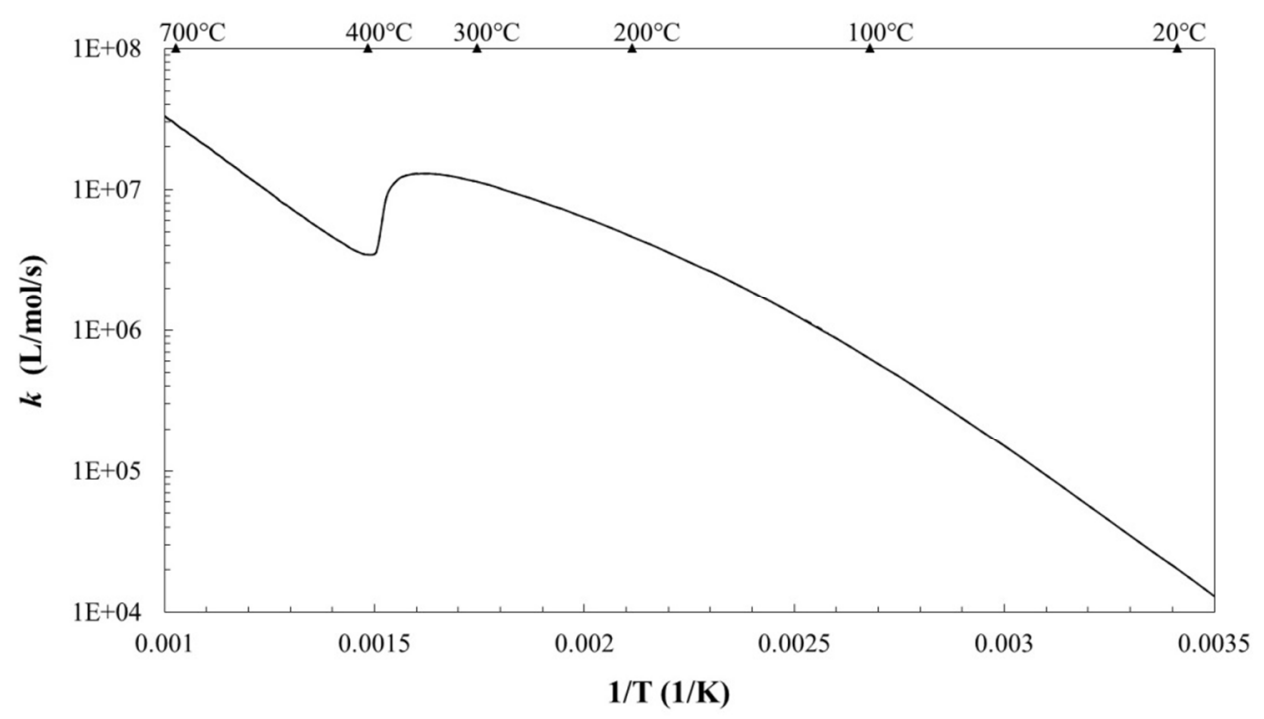

269 Figure 6. The rate constants for this reaction are small compared to other reactions, thus this 270 reaction should not be significant for modeling radiolysis in supercritical water. 


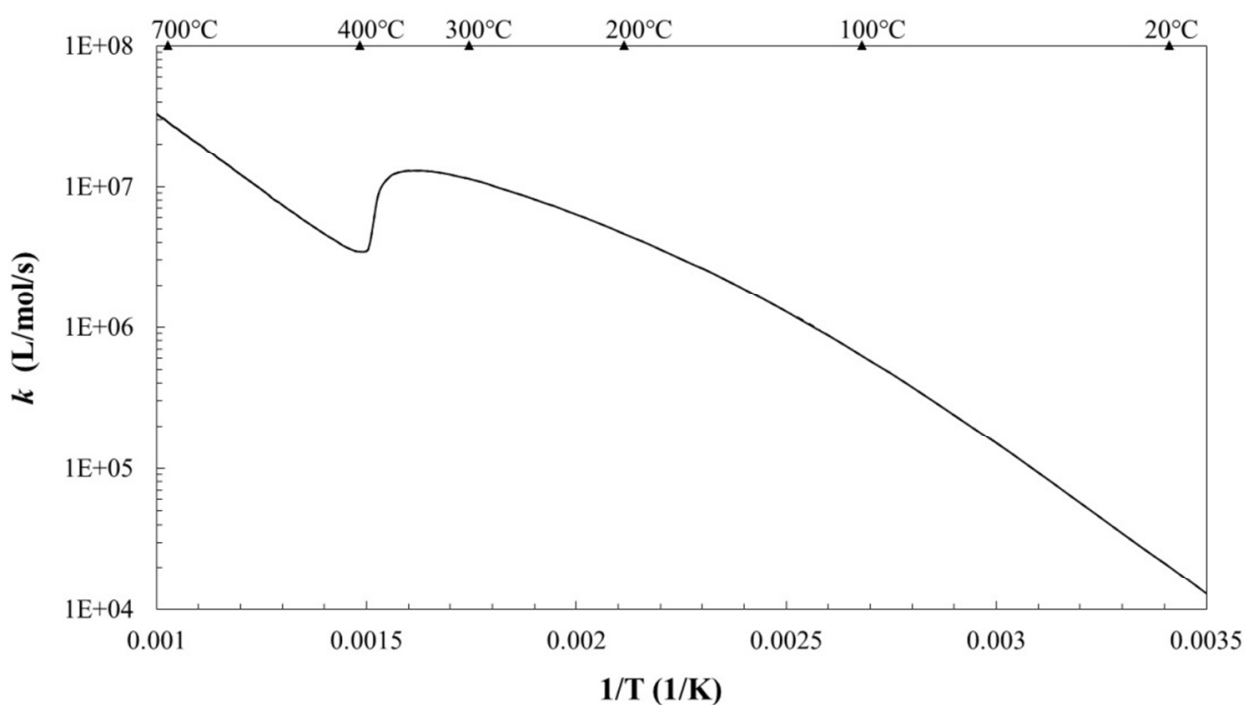

$1 / \mathbf{T}(1 / K)$

272 Figure 6 The predicted rate constants of $\mathrm{R} 15: \mathrm{H} \cdot+\mathrm{O}_{2}^{-} \rightarrow \mathrm{HO}_{2}^{-}$. The parameters used to obtain

273 this curve are described in the text.

275 Among the addition reactions, R3 is the only one not influenced by the cage effect, since for

276 this reaction, only spin orientation is important, not the orientation of the reactant species. Thus,

277 this reaction is diffusion controlled, hence we used Kallikragas diffusion model. However, the

278 addition reaction is in competition with the spin exchange, thus we also included a statistical

279 factor to account for the spin exchange.

280 Among the addition reactions in this category, Reaction R4 and R15 are activation controlled

281 reactions in all temperature ranges. Although Reaction R6, R7, R9, R11, R13 and R14 are all

282 diffusion-controlled reactions at low temperatures, Reaction R6, R9 and R11 turn into activation-

283 controlled reactions near the critical point, whereas reaction R7 R13 and R14 turn into activation

284 controlled near $150^{\circ} \mathrm{C}$. Different reactions have different shapes of temperature dependency

285 mainly due to the difference in diffusion rate of reaction species, degree of the cage effect on

286 the reactions (that also depends on diffusion constants), as well as the energy barrier and pre- 
287 exponential factor of different reactions. For example, the activation energies for R4 and R7 are

288 about the same, but the pre-exponential factor for R4 is two orders of magnitudes smaller than

$289 \mathrm{R} 7$, causing it to be an activation-controlled reaction for the whole temperature range. Reactions

$290 \mathrm{R} 6$ and $\mathrm{R} 7$ are diffusion controlled at low temperatures, but reaction $\mathrm{R} 7$ is influenced heavily by

291 the cage effect, thus it turns into an activation-controlled reaction at a lower temperature than

292 R6. The Ea and $A$ will influence the overall curvature and the magnitude of the rate constants

293 respectively, whereas $p_{\mathrm{R}} k_{\text {gas }}$ and $B(\mathrm{r})$ (which influences rate constant $k_{\text {diff }}$ ) will determine where

294 the peak will be and the magnitude that the rate constants will decrease to near the critical point.

\subsection{Hydrogen abstraction reactions}

296 Among $\mathrm{H} \cdot$ abstraction reactions, $\mathrm{R} 2$ and $\mathrm{R} 10$ involve reactants of the same charge. Due to

297 Coulomb repulsion, their rate constants drop significantly at high temperatures when the

298 dielectric constant of water is small. These two reactions are not important for the modeling of

299 SCWRs due to their small rate constants in SCW. R2 is described in the text while R10 is

300 described in the SI. Except R5, the rest of the reactions are discussed in the SI due to the small

301 g-value of reactants.

$302 \quad$ R2:

$$
\mathrm{e}_{\mathrm{aq}}^{-}+\mathrm{e}_{\mathrm{aq}}^{-}+\left(2 \mathrm{H}_{2} \mathrm{O}\right) \rightarrow \mathrm{H}_{2}+2 \mathrm{OH}^{-}
$$

303 The bimolecular decay of hydrated electrons have been the subject of many studies since 304 they were first observed using pulse radiolysis in $1962 .{ }^{42}$ Hydrated electrons play important 305 roles in many fields, influencing chemical, ${ }^{43}$ biological,,${ }^{44,45}$ and radiation processes. ${ }^{45}$ Many 306 decades after its discovery, the structural and spectroscopic properties of hydrated electron are 307 still not fully understood. ${ }^{45-50}$-5tps:Naverthelessipthe 
308 studied by Christensen et al..$^{51}$ between 5 and $300^{\circ} \mathrm{C}$ and 140 and 150 bar (Figure 7). This work 309 was done using pulse radiolysis and under high hydrogen pressure, in a high-pressure high310 temperature cell with an initial $\mathrm{pH}$ ranged from 10.9 to 13 , and the final $\mathrm{pH}$ ranged from 10.1 to

311 12.2. In their work, the rate constant showed Arrhenius behavior below $150^{\circ} \mathrm{C}$ and a diffusion

312 activation energy of $23 \mathrm{~kJ} \mathrm{~mol}^{-1}$ was proposed in that range. The reaction rate dropped rapidly

313 between $150^{\circ} \mathrm{C}$ and $250^{\circ} \mathrm{C} .{ }^{52}$ Similar behavior has been reported in the work by Marin et al..$^{52}$

314 Marin et al. studied R2 using pulse radiolysis over the temperature range of 100 to $250^{\circ} \mathrm{C}$, with a 315 pressure of 250 bar in alkaline water of $\mathrm{pH} 10.2$ to 11 , using increments of $25^{\circ} \mathrm{C}$. They reported 316 a maximum rate constant of $5.9 \times 10^{10} \mathrm{M}^{-1} \mathrm{~s}^{-1}$ at $150^{\circ} \mathrm{C}^{52}$ The rate constants decrease rapidly 317 above $250^{\circ} \mathrm{C}$, becoming too small to be reliably measured. ${ }^{52}$ Data from both Stuart and 318 Ouellette ${ }^{53}$ and Marin et al. ${ }^{52}$ was used in Figure 7 . The data above $250^{\circ} \mathrm{C}$ is less reliable due to 319 impurities. ${ }^{52}$ These studies show the limits of experiments that are based on optical 320 spectroscopy for aqueous systems with high pressure and temperature. 


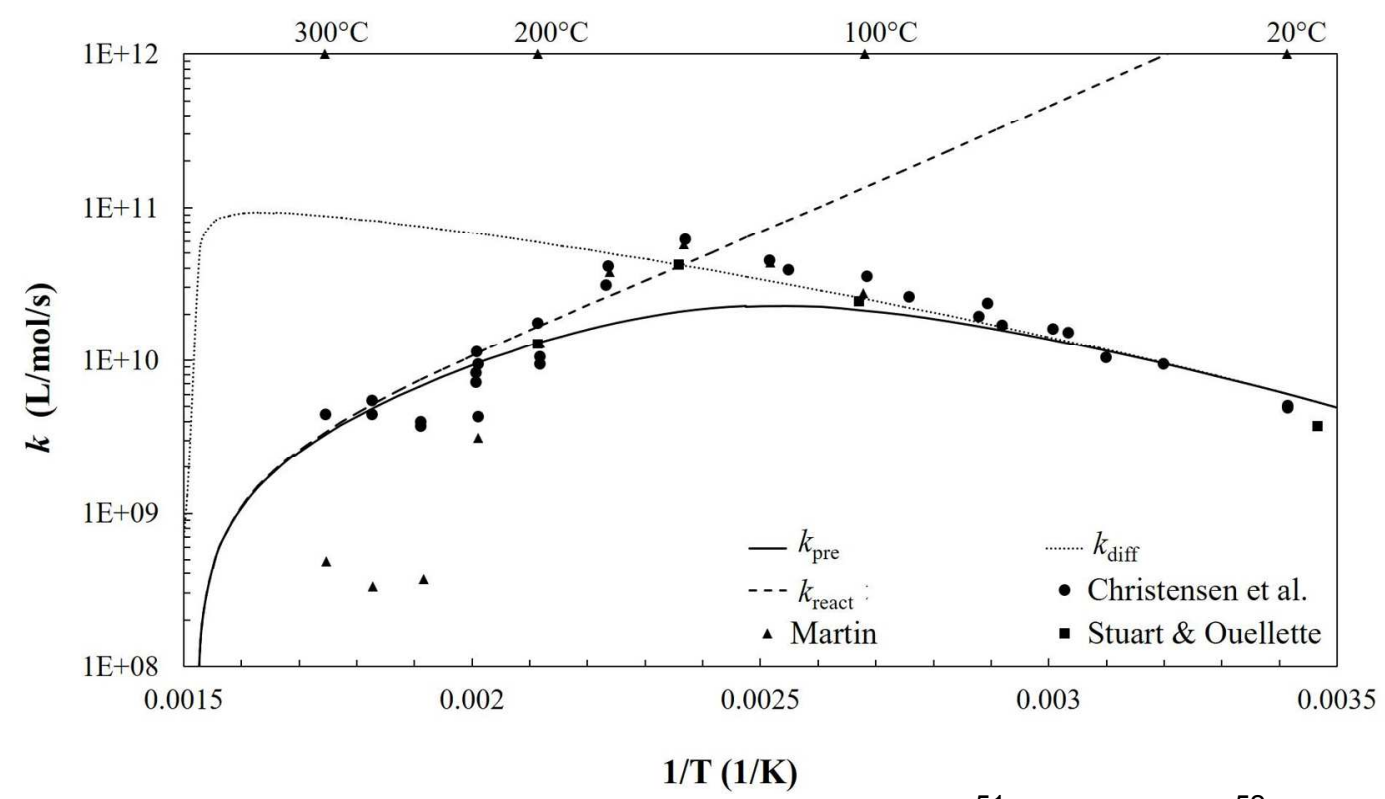

321 Figure 7 The experimental data from Christensen et al. ${ }^{51}$, Marin et al. ${ }^{52}$ and Stuart and

322 Ouellette, ${ }^{53}$ along with our fit of $k_{\text {pre }}$ to the experimental data and its extrapolation to a higher

323 temperatures at 250 bar for $\mathrm{R} 2: \mathrm{e}_{\mathrm{aq}}{ }^{-}+\mathrm{e}_{\mathrm{aq}}{ }^{-}+\left(2 \mathrm{H}_{2} \mathrm{O}\right) \rightarrow \mathrm{H}_{2}+2 \mathrm{OH}^{-}$.

324 Barnett et al. ${ }^{54}$ studied the double electron evolution reaction $\left(\mathrm{H}_{2} \mathrm{O}\right)_{n}^{-2} \rightarrow\left(\mathrm{H}_{2} \mathrm{O}\right)_{n-2}\left(\mathrm{OH}^{-}\right)_{2}+\mathrm{H}_{2}$ 325 experimentally, using mass spectrometry, and computationally using DFT. In their study, ions 326 mass-to-charge ratio was determined for $\left(\mathrm{H}_{2} \mathrm{O}\right)_{n}{ }^{-2}$ water clusters. Only the water clusters that

327 contain more than 105 water molecules have a mass loss of two atomic mass units, indicating a 328 loss of molecular hydrogen. This gives direct evidence of a double electron evolution reaction 329 occurring and shows that this reaction only happens when the water cluster size is larger than $330105 .{ }^{54}$ It also confirms our prediction that this reaction is not important in SCW. Due to the 331 weakening of hydrogen bonding at higher temperatures, ${ }^{18}$ there should be a decrease in the 332 number of larger water clusters. If the cluster size had negative temperature dependence, then it 333 would cause the rate constant of R2 to decrease because R2 requires a water cluster size of 334105 water molecule. A direct attachment of an excess electron on a negatively charged water 335 cluster is inhibited by the large Coulomb barrier and thus, the reaction occurs through the 
336 coalescence of two negative charged water clusters. The two hydrogen atoms from two nearby

337 water molecules in the dielectron hydration cavity approach each other, leading to the formation

338 of a hydrogen molecule.$^{54}$ In this step, the calculated energy of the reaction system reaches a

339 maximum, ${ }^{54}$ thus this step is the bottleneck of the reaction meaning it follows a hydrogen

340 abstraction mechanism. This is then followed by a two proton transfer from the neighboring

341 donor water molecules to solvated electrons that lead to two hydroxide residues. ${ }^{54}$

342 On the other hand, Butarbutar et al ${ }^{55}$ questioned the validity of applying the sudden decrease

343 of the rate constants in alkaline conditions to neutral conditions. They claimed that such a

344 decrease in the rate constants will result in a discontinuity of their fitted $g\left(\mathrm{H}_{2}\right)\left(\mathrm{g}\left(\mathrm{H}_{2}\right)=1\right.$ meaning

345 a single $\mathrm{H}_{2}$ molecule is formed when $100 \mathrm{eV}$ radiation is absorbed by the medium) at $\sim 150^{\circ} \mathrm{C}$ in

346 their low and high linear energy transfer modeling calculations, and that this discontinuity is not

347 observed in experimental data. They suggested a further measurement of rate constants of this

348 reaction in pure water above $\sim 100^{\circ} \mathrm{C}$. It has been shown in many works that the reaction of

$349 \mathrm{R} 32 \mathrm{r}: \mathrm{H} \cdot+\mathrm{H}_{2} \mathrm{O} \rightarrow \mathrm{H}_{2}+\cdot \mathrm{OH}$ becomes significantly important at high temperatures. ${ }^{19,56-58}$ With

350 this additional channel for $\mathrm{H}_{2}$ formation, the discontinuity of $\mathrm{g}\left(\mathrm{H}_{2}\right)$ could be removed though

351 (discussed in detail in section 2.6).

352 We applied our model to this reaction, which resulted in a fair fit as shown in Figure 7. In

353 Barnett's work, an upper bound for activation barrier of $1.8 \mathrm{eV}$ was proposed based on

354 calculations ${ }^{54}$. This is significantly higher than what we would expect from our fit, or from a

355 diffusion-controlled reaction at room temperature. This is not consistent with the large rate

356 constants observed. The activation energy from other sources, which are obtained from fitting

357 experimental data, are close to the activation energy of self-diffusion of water. ${ }^{51-53}$ These

358 predictions similar to ours are significantly lower than the value from Barnett's theoretical study. 
359 As such we believe the proton/electron transfer reaction is significantly affected by quantum 360 tunneling at lower temperatures and that there should be a switch from $E_{\mathrm{a}}$ close to 0 to a large

361 value above the critical point of water, where the large cluster size cannot be accommodated.

362 Furthermore, due to the decrease of the dielectric constant, both the $F_{\mathrm{D}}$ term and $e^{\frac{r_{c}}{R}}$ term

363 (associated with the Debye factor that account for the change in dielectric constant for reactions

364 of charged species. This is described in detail in the SI) increase by a factor of 5 from room

365 temperature to above the critical point. As a result, the $k_{\text {react }}$ and $k_{\text {diff }}$ decreased significantly as

366 shown in Figure 7. We expect the rate constants of this reaction to drop dramatically at high

367 temperatures. We do not consider this reaction significant in SCW.

$368 \quad$ R5:

$$
\mathrm{e}_{\mathrm{aq}}^{-}+\mathrm{H} \cdot\left(+\mathrm{H}_{2} \mathrm{O}\right) \rightarrow \mathrm{H}_{2}+\mathrm{OH}^{-}
$$

369 The reaction of a hydrated electron with an $\mathrm{H} \cdot$ atom produces $\mathrm{H}_{2}$ and $\mathrm{OH}^{-}$. The products of 370 this reaction are similar to those of R2, but this reaction only involves a single hydrated electron.

371 This reaction has been studied in three laboratories. ${ }^{29,52,59}$ These studies are based on the

372 hydrated electron extinction coefficient $18400 \mathrm{~L} \mathrm{~mol}^{-1} \mathrm{~cm}^{-1}$ at maximum absorbance wavelength,

373 which was corrected to $22700 \mathrm{~L} \mathrm{~mol}^{-1} \mathrm{~cm}^{-1}$ by the work of Elliot and Ouellette. ${ }^{60}$

374 One of the proposed mechanism of R5 is shown in Figure 8. In this proposed mechanism, 375 orientation should be an important factor. Orientation sensitive reactions are influenced by the 376 cage effect, and the rate constants drop near the critical point. Tunneling can be a factor for this 377 reaction as well, but that is more important at a lower temperature range. The work from Janik 378 and Bartels also indicates that the rate constant of R5 from Marin is too high above $250^{\circ} \mathrm{C}$. $^{8}$ The 
379 significant increase of Marin's data above $250^{\circ} \mathrm{C}$ could be due to systematic error (eg. high 380 concentration of impurity due to corrosion at high temperature), thus is omitted in our fit.

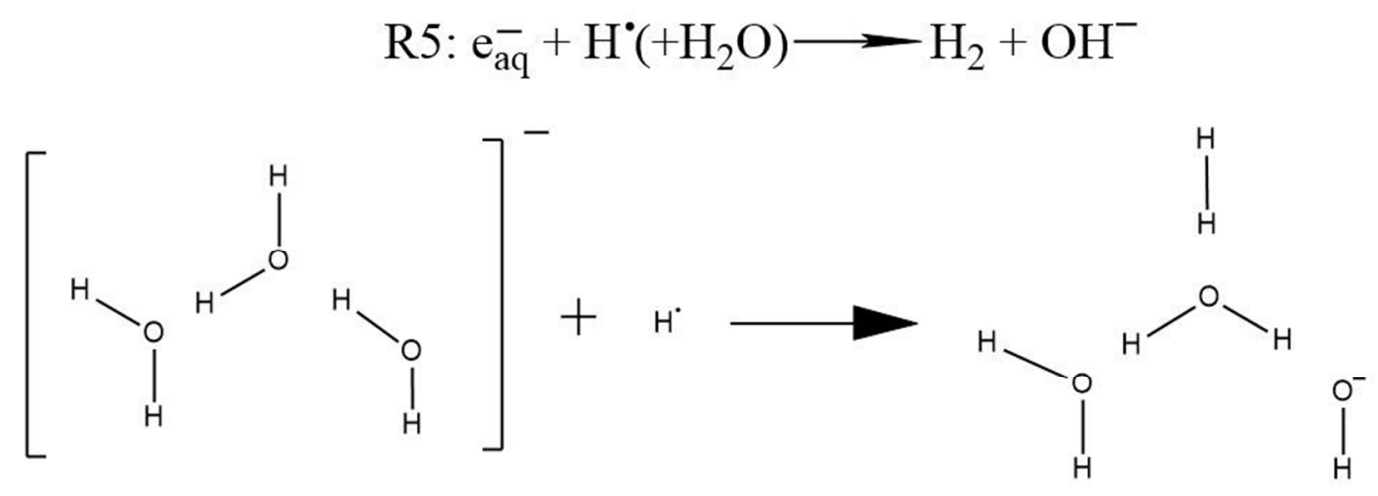

382 Figure 8 proposed mechanism for $\mathrm{R} 5 . \mathrm{H}$. atom has to come to close to the $\mathrm{O}-\mathrm{H}$ bond on the 383 top transfer an $\mathrm{H} \cdot$ to form $\mathrm{H}_{2}$, followed by a proton transfer from a nearby water.

384 Christensen et $a .^{29}$ extracted the data by fitting the decay of hydrated electron absorption in 385 water containing dissolved hydrogen, which turns hydroxyl radicals into hydrogen atoms in near 386 neutral pH solution in the pressure range of 90 to 140 bar. Schwarz ${ }^{59}$ studied R5 in the 387 temperature range of 4 to $65^{\circ} \mathrm{C}$ and used pulse radiolysis to find a rate constant of $3.4 \times 10^{10}$ $388 \mathrm{~L} / \mathrm{mol} / \mathrm{s}$ and an activation energy of $16.1 \mathrm{~kJ} \mathrm{~mol}^{-1}$ at $25^{\circ} \mathrm{C}$. This data was collected in hydrogen389 saturated solutions buffered between $\mathrm{pH} 8.0$ and 8.35 with mixtures of boric acid and sodium 390 tetraborate. ${ }^{59}$ We obtained an activation energy of $5.0 \mathrm{~kJ} \mathrm{~mol}^{-1}$ for this reaction. 
391 The rate constant of R5 slowly reaches a peak around $300^{\circ} \mathrm{C}$ and decreases slowly until it 392 reaches the region near the critical point, where it then rapidly decreases and follows Arrhenius 393 behavior thereafter. This reaction is a diffusion-controlled reaction at low temperatures, but it 394 changes to an activation-controlled as shown in Figure 9. Compared to R3, which is the 395 recombination of $\mathrm{H} \cdot$ atoms, in $\mathrm{R} 5$ a hydrated electron is reacting with an $\mathrm{H} \cdot$ atom. The observed 396 rate constant for $\mathrm{R} 5$ is one order of magnitude higher than $\mathrm{R} 3$, and they are both diffusion397 controlled below $300^{\circ} \mathrm{C}$.

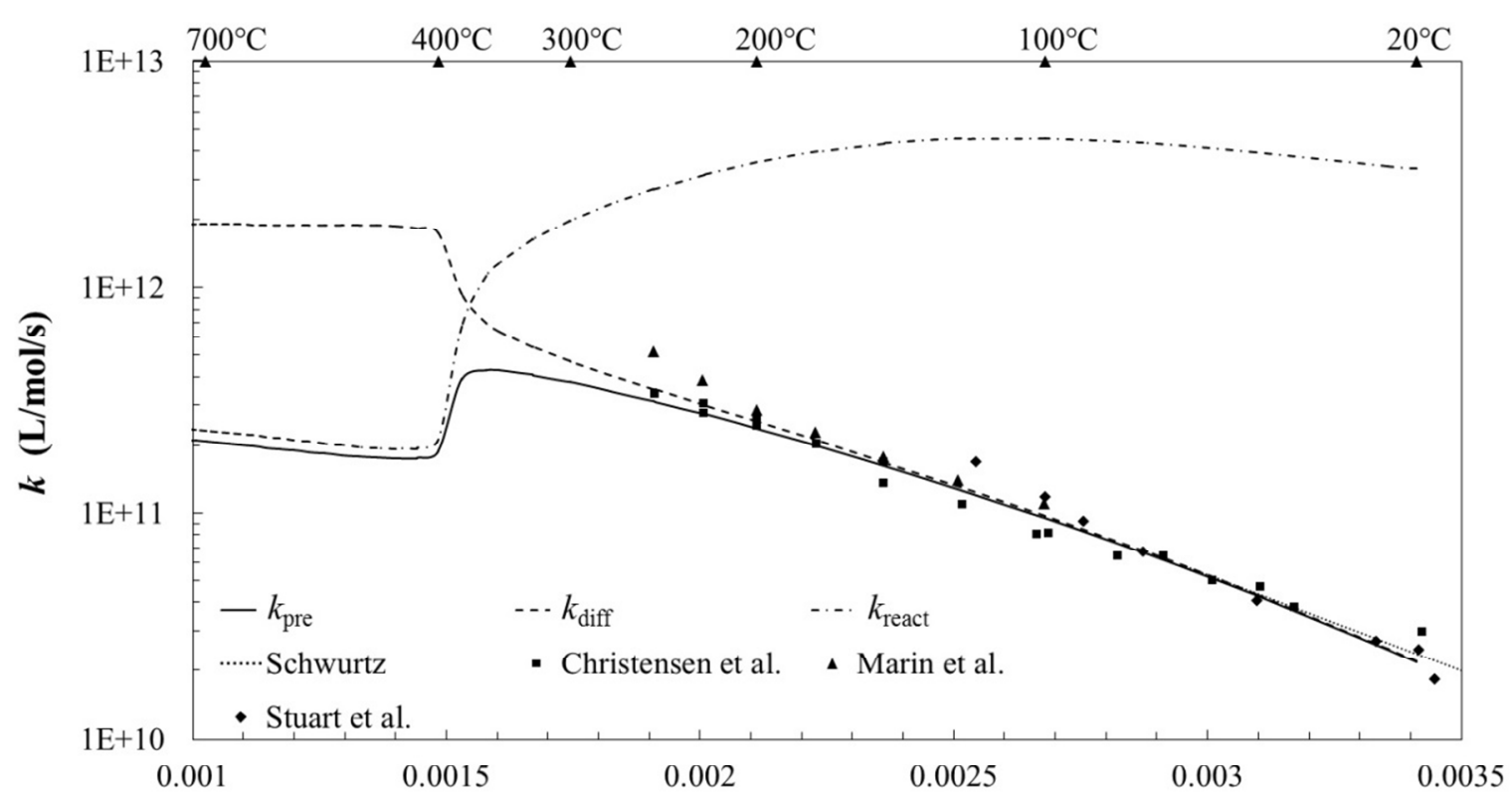

$1 / \mathrm{T}(1 / \mathrm{K})$

398 Figure 9 The experimental data from Marin et $a I^{52}$, Schwurtz $^{59}$, Stuart et al. ${ }^{8}$, and Christensen 399 et al. ${ }^{29}$, along with our fit of $k_{\text {pre }}$ to the experimental data and extrapolation to high temperatures 400 for $\mathrm{R} 5: \mathrm{e}_{\mathrm{aq}}{ }^{-}+\mathrm{H}^{\cdot} \cdot\left(+\mathrm{H}_{2} \mathrm{O}\right) \rightarrow \mathrm{H}_{2}+\mathrm{OH}^{-}$. A pressure of 250 bar was used to produce the figure.

401 Although diffusion coefficients of $\mathrm{H} \cdot$ and $\mathrm{e}_{\mathrm{aq}}{ }^{-}$are of the similar order of magnitude above $402200^{\circ} \mathrm{C}$ (this number is larger for hydrated electrons), Marin suggested that the diffusion rate of 403 the hydrated electron is a factor of 3 times larger than extrapolated from lower temperatures at 
$404300^{\circ} \mathrm{C} .^{52}$ Therefore, the reason that reaction R5 is faster than R3 at these temperatures is likely

405 due to a faster diffusion rate of the hydrated electron rather than a larger reaction distance.

\section{Comparison of different Hydrogen abstraction reactions}

407 The rate constants of Reaction R2 and R10 drop significantly at high temperatures due to 408 Coulomb interaction, thus, they should be insignificant in SCWRs. R5 is diffusion-controlled 409 below the critical point. However, orientation is an important factor for this reaction, thus it is 410 heavily influenced by the cage effect and the reaction becomes activation controlled above the

411 critical point. R16, R19 and R20 are all activation-controlled reactions that are influenced by the 412 cage effect, their rate constants decrease near the critical point similar to R4. The shape of this 413 type of temperature dependency is discussed in section 2.2 .

\subsection{Addition dissociation / Dissociative attachment}

415 All reactions in this category involved two processes -addition and dissociation. The reactions 416 in this section are less important than Reaction R3, R4, R5, R6 and R7 due to the small g417 values of some reactants, thus they are discussed in the SI. At low temperatures, some 418 reactions are activation-controlled and some reactions are diffusion-controlled. Above the critical 419 point, all the addition dissociation/dissociative attachment reactions are activation-controlled due 420 to the cage effect. This type of temperature dependency is discussed in detail in section 2.2.

\subsection{Dissociation}

422 There is only one reaction in this category. The g-value of the reactant, $\mathrm{H}_{2} \mathrm{O}_{2}$, is expected to 423 be lower than those of $\cdot \mathrm{OH}, \mathrm{e}_{\mathrm{aq}}{ }^{-}, \mathrm{H} \cdot$ and $\mathrm{H}_{2}$ in SCW as described in section 2.6, thus this 424 reaction is discussed in the SI. 


\subsection{General discussion of the temperature dependence}

426 Here we include both equilibrium and non-equilibrium reactions. The most important reactions

427 are those that involve water molecules because there is a high concentration of water. These

428 reactions can be particularly important at high temperatures; for example, R32r becomes the

429 main channel for $\cdot \mathrm{OH}$ and $\mathrm{H}_{2}$ formation at elevated temperatures. Transient species that we

430 need to pay attention to are $\mathrm{e}_{\mathrm{aq}}{ }^{-}, \mathrm{H}_{2}, \mathrm{H} \cdot$ and $\cdot \mathrm{OH}$, as experimental data suggests they are the

431 major radiolysis species produced at around $350{ }^{\circ} \mathrm{C} .{ }^{8} \mathrm{We}$ find that the reactions, $\mathrm{R} 30 \mathrm{f}, \mathrm{R} 23 \mathrm{r}$ and

432 other reactions that involve opposite charged reactants have the highest rate constants above

433 the critical point. The rate constants for the reactions studied in this series over the temperature

434 range of 20 to $900^{\circ} \mathrm{C}$ at a pressure of 250 bar are plotted in Figure 10 andFigure 11.

435 Note that the lower rate constants doesn't mean these reactions are not important; e.g. R32r

436 is one of the most important reactions in supercritical water radiolysis. ${ }^{56,57,61}$ The reactions that

437 involve oppositely charged reactants need more attention, as our prediction shows the rate

438 constants for this type of reactions increase dramatically at high temperatures. ${ }^{7}$ An example of

439 this type of reaction is R30f. R30f needs special attention because it might be the cause of the

440 increase of $\mathrm{H}$. atom yield in SCW compared to vapor. The significant increase of the rate

441 constants for these reaction types is caused by the attractive force between the reactants in a

442 low dielectric constant medium. The reverse reactions of these are slowed down very

443 significantly in SCW. ${ }^{7}$ For reactions that involve charged reactants, a further modification,

444 including the effect of the dielectric constant, was also needed. This was done by adding a

445 Debye correction factor. 


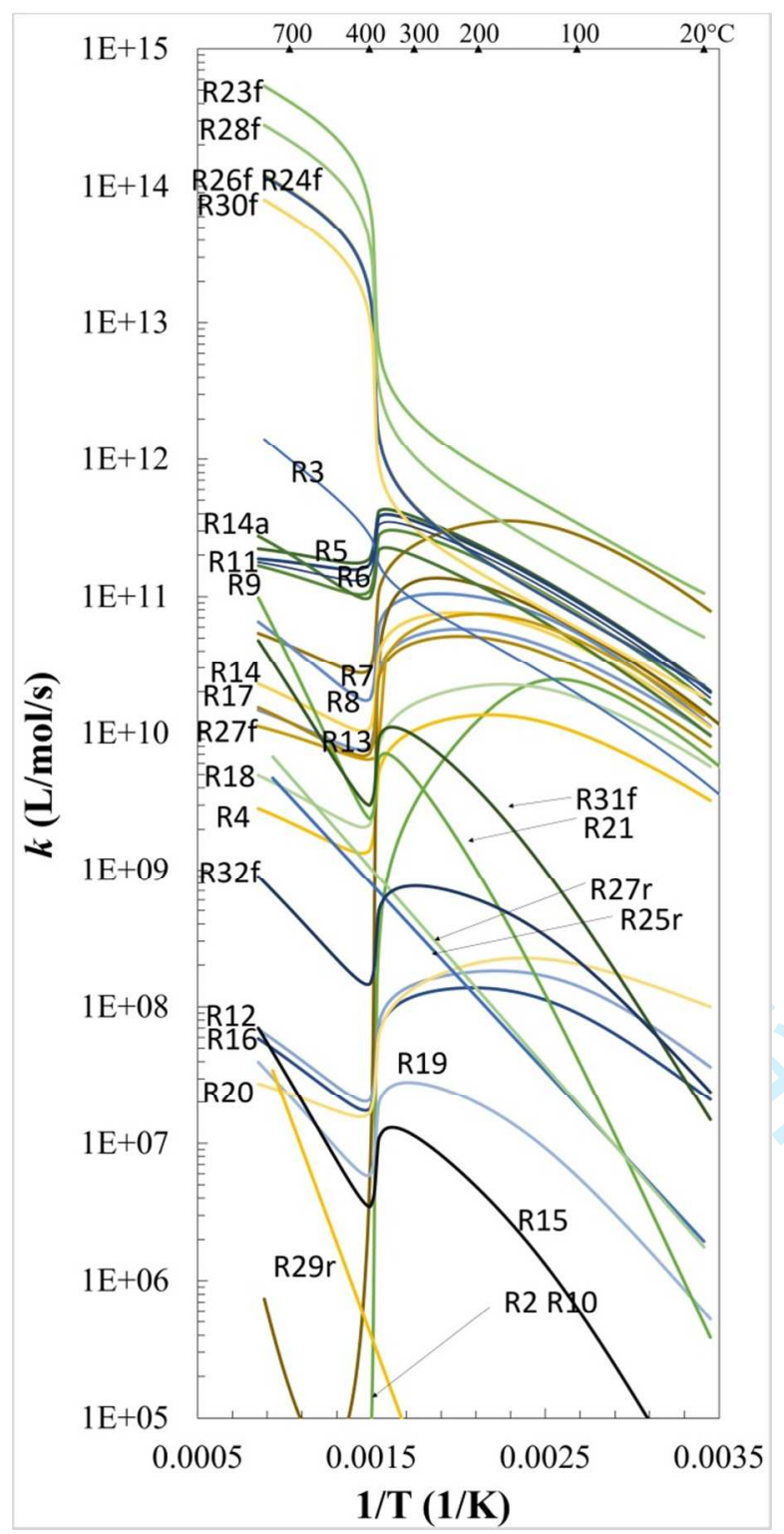

447 Figure 10 The plot of $k_{\text {pre }}$ for all the reactions that were studied in this series with a 448 temperature range of 20 to $900^{\circ} \mathrm{C}$ at a pressure of 250 bar (the reactions with lower rate 449 constants are shown in Figure 11. 


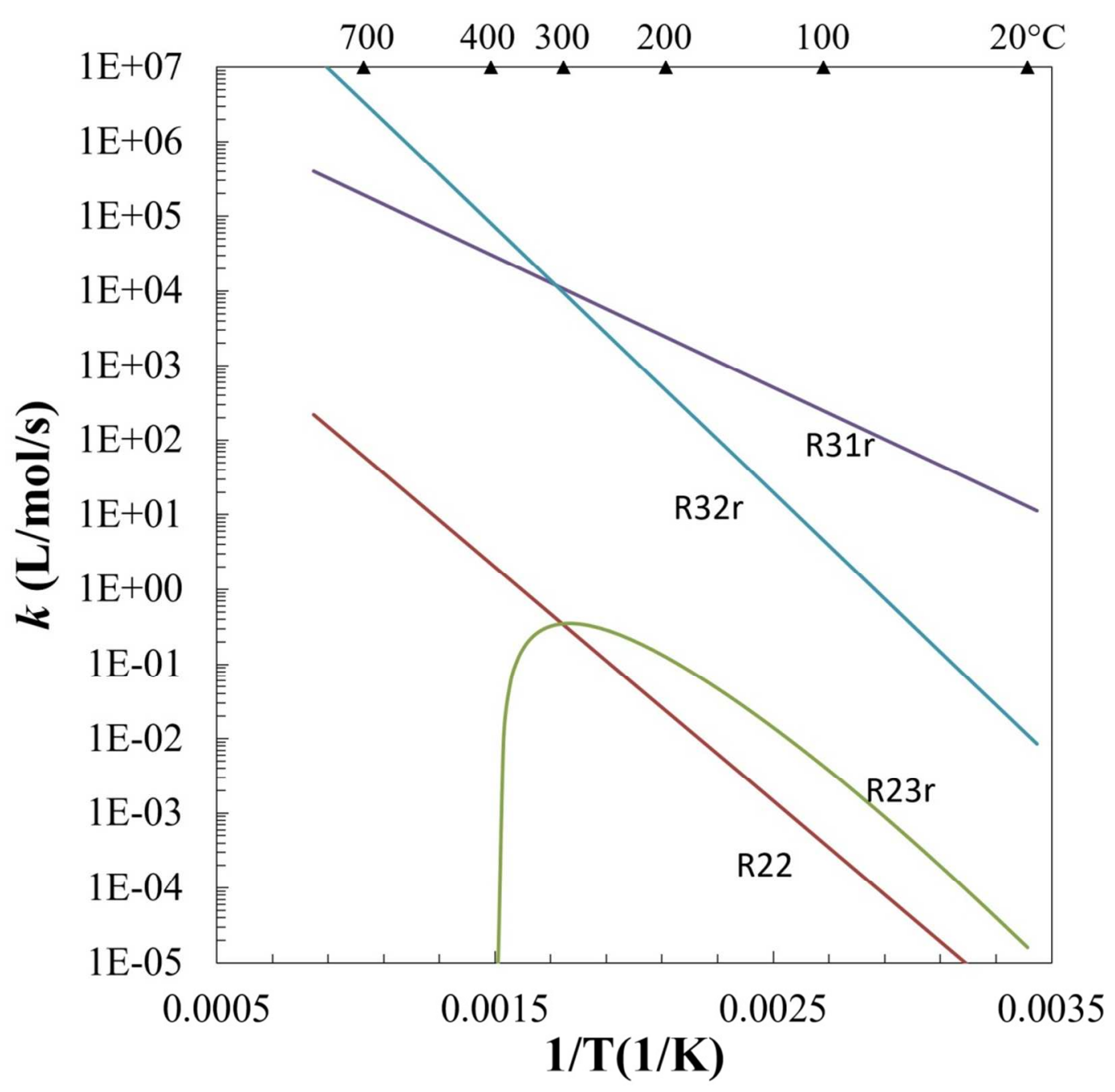

\section{$\mathbf{1} / \mathbf{T}(\mathbf{1} / \mathbf{K})$}

451 Figure 11 The rate constants for reactions that have lower rate constants than the reactions in

452 Figure 10. Reactions like R23r (and R24r, R26r, R28r) are insignificant in supercritical water due 453 to the decreases of the dielectric constant, which describe how well a medium supports ions.

454 The rate constants of R23r are shown in the figure as an example; others are not shown.

455 The rate constants of $\mathrm{R} 2$ decrease significantly above $150^{\circ} \mathrm{C}$. This sudden drop in rate 456 constants reduces the formation of $\mathrm{H}_{2}$ through this channel. $\mathrm{R} 32 \mathrm{r}$, on the other hand, becomes 457 the significant channel for $\mathrm{H}_{2}$ formation at high temperature. The $\mathrm{H}_{2}$ formed through $\mathrm{R} 32 \mathrm{r}$ will 458 balance the effect of a decreasing rate constant of R2, so we predict that the g-value of $\mathrm{H}_{2}$ will 
459 continuously increase ${ }^{56,62}$ We expect the yield of $\mathrm{H}_{2}$ to further increase at higher SCWR

460 temperatures. Bartels et al. proposed that the spur recombination reactions that produce $\mathrm{H}_{2}$ are

461 mainly through the channel of $\mathrm{R} 2, \mathrm{R} 3$, and $\mathrm{R} 5 .{ }^{63}$ They conclude that the g-value of $\mathrm{H}_{2}$ is mainly

462 caused by a pre-solvation event rather than spur recombination events using $\mathrm{NO}_{3}{ }^{-}$and $\mathrm{Cr}_{2} \mathrm{O}_{7}{ }^{2-}$

463 as a hydrated electron scavengers, completely ignoring the effect of R32r. ${ }^{63}$ They cited an

464 unpublished manuscript which suggests the g-value of $\mathrm{H}_{2}$ remains unchanged with $\mathrm{H}$. atom

465 scavenger phenol, which suggests the reaction R32 $r$ is not the cause of the increasing g-value

466 of $\mathrm{H}_{2}$ at high temperature. ${ }^{63} \mathrm{We}$, however, could not find this source, and we are not convinced

467 R32r is not important at high temperatures.

468 In a recent study by Katsumura's group, ${ }^{64}$ the concentration of $\mathrm{O}_{2}$ produced in their simulation 469 was increased by a factor of 100 if they used a rate constant for R32r of more than $10^{3} \mathrm{M}^{-1} \mathrm{~s}^{-1}$

470 rather than neglecting the rate constant of $\mathrm{R} 32 r^{.64}$ They suggested that the $\cdot \mathrm{OH}$ radicals

471 produced from $\mathrm{R} 32 \mathrm{r}$ can react via $\mathrm{R} 16$ to produce $\mathrm{HO}_{2}$, which is the source of $\mathrm{O}_{2}$ production. ${ }^{64}$

472 Thus, $\mathrm{R} 32 \mathrm{r}$ is a very important reaction for determining the yield of $\mathrm{O}_{2}$ in water radiolysis. We

473 have experimentally determined the rate constant of $R 32 \mathrm{r}$ to be around $10^{4} \mathrm{M}^{-1} \mathrm{~s}^{-1}$ at $400^{\circ} \mathrm{C}$

474 using the muon method. ${ }^{19}$ In a recent pulse radiolysis study by Muroya et al. ${ }^{58}$ R32r was

475 studied by using I as a scavenger for $\mathrm{OH} \cdot$, by which an absorption spectrum of the produced $\mathrm{I}_{2}$

476 was gathered. At $350^{\circ} \mathrm{C}$, they found a rate constant for this reaction to be slightly larger than but

477 consistent with what we predicted. ${ }^{58}$ These experiential result show that $R 32 \mathrm{r}$ is a very important

478 reaction in water radiolysis at high temperatures. We have developed a muon spin resonance

479 setup that can further increase the limit of our study to at least $550{ }^{\circ} \mathrm{C}$ at 250 bar. ${ }^{17}$ Experimental

480 data on R32r in this temperature and pressure range will be available soon. 
481 The $\mathrm{H}_{2} \mathrm{O}_{2}$ is mainly formed through the channel $\mathrm{R} 4$ at lower temperatures. ${ }^{61}$ Due to the cage 482 effect, the rate constants for R4 will be lower above the critical point. As such we predict that the 483 g-value of $\mathrm{H}_{2} \mathrm{O}_{2}$ should be low above the critical point.

484 At high temperatures, the rate constants of the main reactions that consume $\cdot \mathrm{OH}$, namely $\mathrm{R} 4$, 485 R6, R7, and R27f, are decreased. However, the reverse reaction of R32r becomes a significant 486 channel that produces $\cdot \mathrm{OH}$ radical and $\mathrm{H}_{2}$, so it is likely that the concentration of $\cdot \mathrm{OH}$ will be 487 continuously increasing in SCW as temperature increases. Concerning $\mathrm{H}_{2}$ production, less is 488 formed through the channel of the R3 and R5 as a result of the cage effect. Above the critical 489 point, we expect R30f to be very significant, which will turn $\mathrm{H}^{+}$and $\mathrm{e}_{\mathrm{aq}}{ }^{-}$to $\mathrm{H} \cdot(\mathrm{R} 30 \mathrm{f}$ is likely the 490 cause of the decrease in g-value of $\mathrm{e}_{\mathrm{aq}}{ }^{-}$at around $300^{\circ} \mathrm{C}^{8}$ ), this together with R32f will very 491 likely to increase the g-value of $\mathrm{H}_{2}$ and $\mathrm{OH}$ radical in SCW dramatically. On the other hand, 492 since the dielectric constant, which describes how well a solvent can support ions, decreases 493 with temperature in water, we expect the g-value for $\mathrm{e}_{\mathrm{aq}}{ }^{-}$to continue decreasing above the 494 critical point. However, $\mathrm{e}_{\mathrm{aq}}{ }^{-}$is still a very important radiolysis species that should be studied very 495 carefully, since it is initially largely produced in the spur $\left(\sim 10^{-12} \mathrm{~s}\right)$, and then are consumed 496 through other reactions (from $\sim 10^{-12} \mathrm{~s}$ to $\sim 10^{-6} \mathrm{~s}$ ). ${ }^{6}$ The decrease in its g-value is likely due to 497 being largely consumed through the channel of R30f. R7 is an important reaction. The yields for 498 both of the reactants increase as the temperature increases to the critical point. ${ }^{8}$ Both reactants 499 could be produced a lot in SCW radiolysis. The two data sets we used to fit R7 are parallel, but 500 one has consistently higher rate constants than the other. Re-measurement is recommended 501 using the up-to-date extinction coefficients.

502 The reactions that did not have any existing data are R11, R15, R24f, R26f, R25f, and R29f. 503 The reactions that have single data points are R10, R27, and R28. Among these reactions, R24f, 
504 R26f, and R28f involve oppositely charged reactants. Those three reactions are expected to be

505 very fast at high-temperatures, and they should be treated with special attention. More

506 theoretical studies on reactions that involve oppositely charged reactants need to be done in

507 order to better understand the radiolysis of water. This can be done based on knowledge of

508 these types of reactions in other solvents. Our group is doing more studies on these types of

509 reactions. Additional correction to critical fluctuation is needed in order to more accurately model

510 the behavior of the reactions at conditions close to maximum compressibility. ${ }^{19,67,68,72}$ Also,

511 influences of $\mathrm{pH}$ on rate constants for each reaction need to be considered. For example,

512 SCWRs will operate in nearly-neutral water, and nearly-neutral water would more readily go

513 through R20 than R19. It is therefore particularly important to make sure the rate constants

514 apply to nearly-neutral water in future work. The recommended rate constants for non-

515 equilibrium reactions $\mathrm{R} 2$ to $\mathrm{R} 22 \mathrm{a}$ in a temperature range of 400 to $800^{\circ} \mathrm{C}$ with a pressure of 250

516 bar are provided in table format (Tables S3 and S4) in the SI.

\subsection{General discussion of the pressure dependence}

518 Most of the experimental data are at a low-temperature range, below $300^{\circ} \mathrm{C}$. The pressures

519 used in each individual experiment varied and were usually significantly lower than the pressure

520 needed for SCWR. The first question is on the validity of such experimental data and models

521 based on them for higher pressures. Pressure does not have a significant effect on rate

522 constants at low temperatures. This is demonstrated in Figure 12 which shows the reproduced

523 rate constants of fitted $\mathrm{R} 17$ at different pressures. 


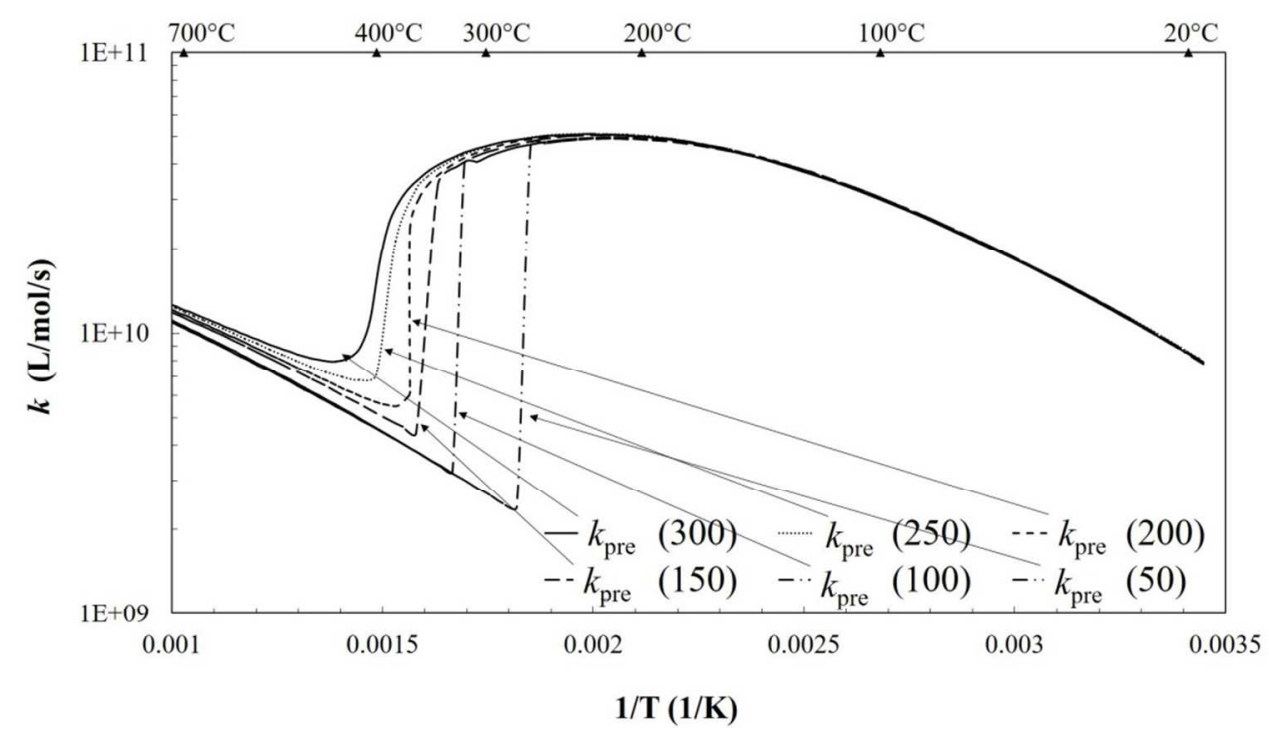

524 Figure 12 The rate constants of R17 at different pressures. Notice that although the rate

525 constants are significantly different at high-temperature ranges at different pressures, the rate 526 constants do not vary much with pressure at low temperatures.

527 Notice that although pressure has significant effects on rate constants at high temperatures,

528 the rate constants overlap at low temperatures. This show that pressure has very little influence

529 on rate constants below $300^{\circ} \mathrm{C}$. Unless there is a phase change where the pressure is not

530 sufficient for water to maintain its liquid form, the rate constants are practically pressure

531 independent at low temperatures under $300^{\circ} \mathrm{C}$. This is important because many experimental

532 works do not report the pressure used. Based on Figure 12, the data from low-temperatures can

533 be used regardless of pressure. Also, as shown in our previous work, ${ }^{7}$ although Yoshida's

534 diffusion coefficient experimental data is taken from different pressures, all data points at a low-

535 temperature range (below $300^{\circ} \mathrm{C}$ ) fit the Kallikragas and Stoke-Einstein models for diffusion

536 well. It is, therefore, valid for us to use the rate constants from experiments at low temperatures

537 and pressures to predict the rate constants above the critical point, as long as our model takes

538 into account the effects of the pressure at high temperatures, which it does. The effect of

539 pressure on reaction rate can be inferred from activation volume which is defined as the 
540 difference between the partial molar volumes of the activated complex and the reactants. ${ }^{65}$ From

541 transition state theory, and classical thermodynamics, the pressure-dependent activation

542 volume can be written as:

$$
\left(\frac{\partial \operatorname{Ln}(k)}{\partial P}\right)_{T}=-\frac{\Delta V^{\ddagger}}{R T}+\kappa_{T}
$$

543 where $P$ is the pressure, $R$ is the gas constant, $T$ is the temperature, $\mathrm{k}$ is rate constant, and $\kappa_{T}$

544 is the solvent's isothermal compressibility. ${ }^{66}$

545 Properties such as density, diffusivity of water, compressibility and dielectric constant of the

546 liquid can change significantly with pressure near the critical point. The change of those

547 properties influence reaction kinetics. ${ }^{11,65,67}$ However, away from the critical point, liquid

548 properties are essentially pressure independent. ${ }^{65}$ Based on our studies, ${ }^{11}$ at $205^{\circ} \mathrm{C}$, the

549 isothermal rate constants of $\mathrm{Mu} \cdot$ reacting with $\mathrm{Ni}^{2+}$ in water are essentially pressure

550 independent. However, at $359^{\circ} \mathrm{C}$, we observe a significant pressure dependence. ${ }^{11}$ Similar

551 behavior has been seen for the reaction between $\mathrm{Mu} \cdot$ and hydroquinone in water. ${ }^{11}$ From these

552 previous works we established that activation volumes are only large enough at above $350^{\circ} \mathrm{C}$.

\section{3. Conclusion}

554 Many properties of water depend on temperature and density, and this can significantly change

555 the rate constants of reactions. ${ }^{10,11,13,15,67-80}$ These include the efficiency factor (cage effect), ${ }^{7}$

556 the diffusion rate of different species, and the dielectric constant that influences the reactions of

557 charged species. In this work, we considered all these aspects. The main purpose of this study

558 was to provide recommendations for rate constants of reactions in water past the critical point.

559 We studied important reactions involved in the radiolysis of water using the "cage effect model". 7 
560 The cage effect model describes the drastic non-Arrhenius temperature dependence observed

561 for different chemical reactions in water. The rate constants of many reactions follow Arrhenius

562 temperature dependence at low temperatures. However, due to the cage effect, the reaction

563 efficiency decreases at high temperatures. As a result, the rate constants of these reactions also

564 decrease near the critical point. There is one collision per encounter for chemical reactions at

565 high temperatures in SCW, thus the reaction efficiency remains constant in this high

566 temperature range. Therefore, the rate constants of these reactions increase again and follow

567 an Arrhenius temperature dependence at high temperatures. Our work will enable engineers to

568 better predict the concentration of eroding species in SCWRs and allow them to develop

569 chemical control strategies to minimize corrosion, thus increase the lifetime of the reactors. ${ }^{17}$

\section{4. Acknowledgements}

571 We thank Logan Toth, Rejean Leblanc, Tait Du and John Beninger for early help related to the

572 development of some of our reaction models and Dr. Percival for valuable discussions. This

573 research was financially supported by the Generation IV Energy Technologies Program of the

574 Natural Sciences and Engineering Research Council of Canada and NSERC.

575 5. References:

576 (1) Yetisir, M.; Diamond, W.; Leung, L. K. H.; Martin, D.; Duffey, R. In proceedings of the 5th International Symposium of the Supercritical Water Reactors (ISSCWR-5); Vancouver, 2011.

(2) Generation IV International Forum. A Technology Roadmap for Generation IV Nuclear Energy Systems; Report GIF-002-00, 2002.

(3) Kim, T. K. In Nuclear Energy: Selected Entries from the Encyclopedia of Sustainability Science and Technology; Tsoulfanidis, N., Ed.; Springer New York: New York, NY, 2013; pp 175-201. 
584 (4) Uchida, S.; Katsumura, Y. J. Nucl. Sci. Technol. 2013, 50 (4), 346-362 DOI: 10.1080/00223131.2013.773171.

(5) Cobut, V.; Frongillo, Y.; Patau, J. P.; Goulet, T.; Fraser, M. J.; Jay-Gerin, J. P. Radiat. Phys. Chem. 1998, 51 (3), 229-243 DOI: 10.1016/S0969-806X(97)00096-0.

588

589

590

591

592

593

594

595

596

597

598

599

600

601

602

603

604

605

606

607

608

609

610

611

612

613

614

615

616

(6) Frongillo, Y.; Goulet, T.; Fraser, M.-J.; Cobut, V.; Patau, J. P.; Jay-Gerin, J.-P. Radiat. Phys. Chem. 1998, 51 (3), 245-254 DOI: 10.1016/S0969-806X(97)00097-2.

(7) Liu, G.; Du, T.; Toth, L.; Beninger, J.; Ghandi, K. CNL Nucl. Rev. 2016 DOI: 10.12943/CNR.2016.00035.

(8) A. J. Elliot and D. M. Bartels. The Reaction Set, Rate Constants and G-Values for the Simulation of the Radiolysis of Light Water over the Range 20 to $350^{\circ} \mathrm{C}$ Based on Information Available in 2008; Atomic Energy of Canada Limited, Report,153-127160-450001, 2009.

(9) Brodovitch, J.-C.; McCollum, B. M.; Percival, P. W. Phys. B Condens. Matter 2009, 404 (5-7), 950-952 DOI: 10.1016/j.physb.2008.11.129.

(10) Cline, J.; Takahashi, K.; Marin, T. W.; Jonah, C. D.; Bartels, D. M. J. Phys. Chem. A 2002, 106 (51), 12260-12269 DOI: 10.1021/jp0270250.

(11) Ghandi, K.; Addison-Jones, B.; Brodovitch, J.-C.; McKenzie, I.; Percival, P. W.; Schüth, J. Phys. Chem. Chem. Phys. 2002, 4 (4), 586-595 DOI: 10.1039/b108656a.

(12) Janik, I.; Bartels, D. M.; Marin, T. W.; Jonah, C. D. J. Phys. Chem. A 2007, 111 (1), 79-88 DOI: 10.1021/jp065140v.

(13) Percival, P. W.; Brodovitch, J.-C.; Ghandi, K.; McCollum, B. M.; McKenzie, I. Radiat. Phys. Chem. 2007, 76 (8-9), 1231-1235 DOI: 10.1016/j.radphyschem.2007.02.010.

(14) Ghandi, K.; Addison-Jones, B.; Brodovitch, J. C.; Kecman, S.; McKenzie, I.; Percival, P. W. Phys. B Condens. Matter 2003, 326 (1-4), 55-60 DOI: 10.1016/S09214526(02)01572-7.

(15) Ghandi, K.; Percival, P. W. J. Phys. Chem. A 2003, 107 (17), 3005-3008 DOI: 10.1021/jp027858q.

(16) Lin, M.; Muroya, Y.; Baldacchino, G.; Katsumura, Y. In Recent trend in radiation chemistry; Wishart JF, BSM, R., Eds.; World Scientific Publishing: Singapore, 2010; pp 255-277.

(17) Liu, G.; Chen, Y.; Morrison, A.; Percival, P.; Ghandi, K. In $\mu$ SR2017 conference proceeding; 2017.

(18) Dougherty, R. C. J. Chem. Phys. 1998, 109 (17), 7372-7378 DOI: 10.1063/1.477343. 
617 618

619 620

621

622

623

624

625

626

627

628

629

630

631

632

633

634

635

636

637

638

639

640

641

642

643

644

645

646

647

648

649

(19) Alcorn, C. D.; Brodovitch, J. C.; Percival, P. W.; Smith, M.; Ghandi, K. Chem. Phys. 2014, 435, 29-39 DOI: 10.1016/j.chemphys.2014.02.016.

(20) Janik, I.; Bartels, D. M.; Jonah, C. D. J. Phys. Chem. A 2007, 111 (10), 1835-1843 DOI: 10.1021/jp065992v.

(21) Elliot, A. J.; McCracken, D. R.; Buxton, G. V.; Wood, N. D. J. Chem. Soc. Faraday Trans. 1990, 86 (9), 1539 DOI: 10.1039/ft9908601539.

(22) Zheng, J.; Fayer, M. D. J. Am. Chem. Soc. 2007, 129 (14), 4328-4335 DOI: 10.1021/ja067760f.

(23) Mizan, T. I.; Savage, P. E.; Ziff, R. M. J. Phys. Chem. 1996, 100 (1), 403-408 DOI: 10.1021/jp951561t.

(24) Sehested, K.; Christensen, H. Int. J. Radiat. Appl. Instrumentation. Part C. Radiat. Phys. Chem. 1990, 36 (3), 499-500 DOI: 10.1016/1359-0197(90)90040-O.

(25) Senba, M. Phys. Rev. A 1994, 50 (1), 214-227 DOI: 10.1103/PhysRevA.50.214.

(26) Kallikragas, D. T.; Plugatyr, A. Y.; Svishchev, I. M. J. Chem. Eng. Data 2014, 59 (6), 1964-1969 DOI: 10.1021/je500096r.

(27) Svishchev, I. M.; Carvajal-Ortiz, R. A.; Choudhry, K. I.; Guzonas, D. A. Corros. Sci. 2013, 72, 20-25 DOI: 10.1016/j.corsci.2013.02.005.

(28) Kanike, V.; Meesungnoen, J.; Jay-Gerin, J.-P. RSC Adv. 2015, 5 (54), 43361-43370 DOI: 10.1039/C5RA07173A.

(29) Christensen, H.; Sehested, K.; Logager, T. Radiat. Phys. Chem. 1994, 43 (6), 527-531 DOI: $10.1016 / 0969-806 \times(94) 90163-5$.

(30) Elliot, A. J.; Ouellette, D. C. J. Chem. Soc., Faraday Trans. 1994, 90 (6), 837-841 DOI: 10.1039/FT9949000837.

(31) Lundström, T.; Christensen, H.; Sehested, K. Radiat. Phys. Chem. 2002, 64 (1), 29-33 DOI: 10.1016/S0969-806X(01)00439-X.

(32) Buxton, G. V.; Elliot, A. J. J. Chem. Soc. Faraday Trans. 1993, 89 (3), 485 DOI: 10.1039/ft9938900485.

(33) Swiatla-Wojcik, D.; Buxton, G. V. J. Phys. Chem. 1995, 99 (29), 11464-11471 DOI: 10.1021/j100029a026.

(34) Gaussian 09, Revision A.02, M. J. Frisch, G. W. Trucks, H. B. Schlegel, G. E. Scuseria, M. A. Robb, J. R. Cheeseman, G. Scalmani, V. Barone, G. A. Petersson, H. Nakatsuji, X. Li, M. Caricato, A. Marenich, J. Bloino, B. G. Janesko, R. Gomperts, B. Mennucci, H. P. Hratchian, J. V. Ortiz A. F. Izmaylov J. L. Sonnenberg, D. Williams-Young, F. Ding, F. 
Lipparini, F. Egidi, J. Goings, B. Peng, A. Petrone, T. Henderson, D. Ranasinghe, V. G. Zakrzewski, J. Gao, N. Rega, G. Zheng, W. Liang, M. Hada, M. Ehara, K. Toyota, R. Fukuda, J. Hasegawa, M. Ishida, T. Nakajima, Y. Honda, O. Kitao, H. Nakai, T. Vreven, K. Throssell, J. A. Montgomery, Jr., J. E. Peralta, F. Ogliaro, M. Bearpark, J. J. Heyd, E. Brothers, K. N. Kudin, V. N. Staroverov, T. Keith, R. Kobayashi, J. Normand, K. Raghavachari, A. Rendell, J. C. Burant, S. S. Iyengar, J. Tomasi, M. Cossi, J. M. Millam, M. Klene, C. Adamo, R. Cammi, J. W. Ochterski, R. L. Martin, K. Morokuma, O. Farkas, J. B. Foresman, and D. J. Fox, Gaussian, Inc., Wallingford CT, 2016.

(35) R.G.Parr; W.Yang. Density Functional Theory of Atoms and Molecules; Oxford University Press: Oxford, UK, 1989.

(36) Becke, A. D. J. Chem. Phys. 1993, 98 (7), 5648-5652 DOI: 10.1063/1.464913.

(37) Lee, C.; Yang, W.; Parr, R. G. Phys. Rev. B 1988, 37 (2), 785-789 DOI: 10.1103/PhysRevB.37.785.

(38) Krishnan, R.; Binkley, J. S.; Seeger, R.; Pople, J. A. J. Chem. Phys. 1980, 72 (1), 650654 DOI: $10.1063 / 1.438955$.

(39) Peng, C.; Bernhard Schlegel, H. Isr. J. Chem. 1993, 33 (4), 449-454 DOI: 10.1002/ijch.199300051.

(40) Fernández-Ramos, A.; Miller, J. A.; Klippenstein, S. J.; Truhlar, D. G. Chem. Rev. 2006, 106 (11), 4518-4584 DOI: 10.1021/cr050205w.

(41) Lynch, B. J.; Truhlar, D. G. J. Phys. Chem. A 2001, 105 (13), 2936-2941 DOI: 10.1021/jp004262z.

(42) Marsalek, O.; Uhlig, F.; VandeVondele, J.; Jungwirth, P. Acc. Chem. Res. 2012, 45 (1), 23-32 DOI: 10.1021/ar200062m.

(43) Garrett, B. C.; Dixon, D. A.; Camaioni, D. M.; Chipman, D. M.; Johnson, M. A.; Jonah, C. D.; Kimmel, G. A.; Miller, J. H.; Rescigno, T. N.; Rossky, P. J.; Xantheas, S. S.; Colson, S. D.; Laufer, A. H.; Ray, D.; Barbara, P. F.; Bartels, D. M.; Becker, K. H.; Bowen, K. H.; Bradforth, S. E.; Carmichael, I.; Coe, J. V.; Corrales, L. R.; Cowin, J. P.; Dupuis, M.; Eisenthal, K. B.; Franz, J. A.; Gutowski, M. S.; Jordan, K. D.; Kay, B. D.; LaVerne, J. A.; Lymar, S. V.; Madey, T. E.; McCurdy, C. W.; Meisel, D.; Mukamel, S.; Nilsson, A. R.; Orlando, T. M.; Petrik, N. G.; Pimblott, S. M.; Rustad, J. R.; Schenter, G. K.; Singer, S. J.; Tokmakoff, A.; Wang, L.-S.; Zwier, T. S. Chem. Rev. 2005, 105 (1), 355-390 DOI: 10.1021/cr030453x.

(44) von Sonntag, C. Free-Radical-Induced DNA Damage and Its Repair; Springer Berlin Heidelberg: Berlin, Heidelberg, 2006.

(45) Alizadeh, E.; Sanche, L. Chem. Rev. 2012, 112 (11), 5578-5602 DOI: 10.1021/cr300063r. 
686

687

688

689

690

691

692

693

694

695

696

697

698

699

700

701

702

703

704

705

706

707

708

709

710

711

712

713

714

715

716

717

22-34 DOI: 10.1039/c1cp21803d.

(47) Herbert, J. M.; Jacobson, L. D. Int. Rev. Phys. Chem. 2011, 30 (1), 1-48 DOI: $10.1080 / 0144235 X .2010 .535342$.

(48) Turi, L.; Rossky, P. J. Chem. Rev. 2012, 112 (11), 5641-5674 DOI: 10.1021/cr300144z.

(49) Abel, B. Annu. Rev. Phys. Chem. 2013, 64 (1), 533-552 DOI: 10.1146/annurevphyschem-040412-110038.

(50) Herbert, J. M.; Coons, M. P. Annu. Rev. Phys. Chem. 2017, 68 (1), 447-472 DOI: 10.1146/annurev-physchem-052516-050816.

(51) Christensen, H.; Sehested, K. J. Phys. Chem. 1986, 90 (1), 186-190 DOI: $10.1021 / \mathrm{j} 100273 \mathrm{a} 042$.

(52) Marin, T. W.; Takahashi, K.; Jonah, C. D.; Chemerisov, S. D.; Bartels, D. M. J. Phys. Chem. A 2007, 111 (45), 11540-11551 DOI: 10.1021/jp074581r.

(53) Elliot, A.; Ouellette, D. C.; Stuart, C. R. The Temperature Dependence of the Rate Constants and Yields for the Simulation of the Radiolysis of Heavy Water, Atomic Energy of Canada Limited, Report: AECL-11658, 1996.

(54) Barnett, R. N.; Giniger, R.; Cheshnovsky, O.; Landman, U. J. Phys. Chem. A 2011, 115 (25), 7378-7391 DOI: 10.1021/jp201560n.

(55) Butarbutar, S. L.; Muroya, Y.; Kohan, L. M.; Sanguanmith, S.; Meesungnoen, J.; JayGerin, J.-P. Atom Indones. 2013, 39 (2), 51 DOI: 10.17146/aij.2013.231.

(56) Sanguanmith, S.; Muroya, Y.; Meesungnoen, J.; Lin, M.; Katsumura, Y.; Mirsaleh Kohan, L.; Guzonas, D. a.; Stuart, C. R.; Jay-Gerin, J.-P. Chem. Phys. Lett. 2011, 508 (4-6), 224-230 DOI: 10.1016/j.cplett.2011.04.059.

(57) Swiatla-Wojcik, D.; Buxton, G. V. Radiat. Phys. Chem. 2005, 74 (3-4), 210-219 DOI: 10.1016/j.radphyschem.2005.04.014.

(58) Muroya, Y.; Yamashita, S.; Lertnaisat, P.; Sanguanmith, S.; Meesungnoen, J. Phys. Chem. Chem. Phys. 2017, 19 (45), 30834-30841 DOI: 10.1039/C7CP06010F.

(59) Schwarz, H. A. J. Phys. Chem. 1992, 96 (22), 8937-8941 DOI: 10.1021/j100201a044.

(60) Hare, P. M.; Price, E. a; Bartels, D. M. J. Phys. Chem. A 2008, 112 (30), 6800-6802 DOI: $10.1021 / \mathrm{jp} 804684 \mathrm{w}$.

(61) Sanguanmith, S.; Meesungnoen, J.; Jay-Gerin, J.-P. Chem. Phys. Lett. 2013, 588, 82-86 DOI: 10.1016/j.cplett.2013.09.057.

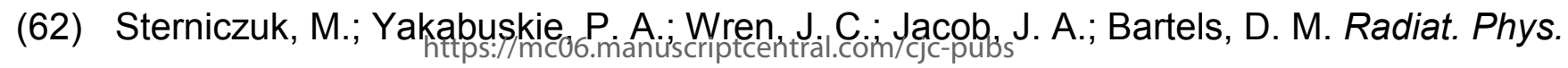


718

719

720

721

722

723

724

725

726

727

728

729

730

731

732

733

734

735

736

737

738

739

740

741

742

743

744

745

746

747

748

749

Chem. 2016, 121, 35-42 DOI: 10.1016/j.radphyschem.2015.12.007.

(63) Sterniczuk, M.; Bartels, D. M. J. Phys. Chem. A 2016, 120 (2), 200-209 DOI: 10.1021/acs.jpca.5b12281.

(64) Lertnaisat, P.; Katsumura, Y.; Mukai, S.; Umehara, R.; Shimizu, Y.; Suzuki, M. J. Nucl. Sci. Technol. 2016, 53 (11), 1816-1823 DOI: 10.1080/00223131.2016.1165636.

(65) Wu, B. C.; Klein, M. T.; Sandler, S. I. Ind. Eng. Chem. Res. 1991, 30 (5), 822-828 DOI: 10.1021/ie00053a003.

(66) Savage, P. E.; Gopalan, S.; Mizan, T. I.; Martino, C. J.; Brock, E. E. AlChE J. 1995, 41 (7), 1723-1778 DOI: 10.1002/aic.690410712.

(67) Ghandi, K.; McFadden, R. M. L.; Cormier, P. J.; Satija, P.; Smith, M. Phys. Chem. Chem. Phys. 2012, 14 (24), 8502 DOI: 10.1039/c2cp41170a.

(68) Cormier, P. J.; Clarke, R. M.; McFadden, R. M. L.; Ghandi, K. J. Am. Chem. Soc. 2014, 136 (6), 2200-2203 DOI: 10.1021/ja408438s.

(69) Satija, P.; McFadden, R. M. L.; Cormier, P.; Ghandi, K. Int. Rev. Chem. Eng. 2011, 3 (5), 542-549.

(70) Cormier, P.; Arseneau, D. J.; Brodovitch, J. C.; Lauzon, J. M.; Taylor, B. A.; Ghandi, K. J. Phys. Chem. A 2008, 112 (20), 4593-4600 DOI: 10.1021/jp801023v.

(71) Ghandi, K.; Brodovitch, J.-C.; Addison-Jones, B.; Percival, P. W.; Schüth, J. Phys. B Condens. Matter 2000, 289-290, 476-481 DOI: 10.1016/S0921-4526(00)00440-3.

(72) Cormier, P. J.; Alcorn, C.; Legate, G.; Ghandi, K. Radiat. Res. 2014, 181 (4), 396-406 DOI: $10.1667 / R R 13516.1$.

(73) Legate, G.; Alcorn, C.; Brodovitch, J.-C.; Ghandi, K.; Percival, P. W. In proceedings of the 5th International Symposium of the Supercritical Water Reactors (ISSCWR-5); 2011.

(74) Ghandi, K.; Alcorn, C.; Legate, G.; Percival, P. W.; Brodovitch, J.-C. In proceedings of the second Canada-China Joint Conference on Supercritical Water-Cooled Reactors; 2010.

(75) Lin, M.; Katsumura, Y.; Muroya, Y.; He, H.; Wu, G.; Han, Z.; Miyazaki, T.; Kudo, H. J. Phys. Chem. A 2004, 108 (40), 8287-8295 DOI: 10.1021/jp048854j.

(76) Muroya, Y.; Lin, M.; de Waele, V.; Hatano, Y.; Katsumura, Y.; Mostafavi, M. J. Phys. Chem. Lett. 2010, 1 (1), 331-335 DOI: 10.1021/jz900225a.

(77) Bartels, D. M.; Takahashi, K.; Cline, J. A.; Marin, T. W.; Jonah, C. D. J. Phys. Chem. A 2005, 109 (7), 1299-1307 DOI: 10.1021/jp0457141.

(78) Percival, P. W.; Brodovitch J J-C.: Ghandi, K.; Addison-Jones, B.; Schüth, J.; Bartels, D. 
M. Phys. Chem. Chem. Phys. 1999, 1 (21), 4999-5004 DOI: 10.1039/a906925i.

751

(79) Bulemela, E.; Tremaine, P.; Ikawa, S. Fluid Phase Equilib. 2006, 245 (2), 125-133 DOI: 10.1016/j.fluid.2006.05.007.

753

754

(80) Zimmerman, G. H.; Arcis, H.; Tremaine, P. R. J. Chem. Eng. Data 2012, 57 (11), 31803197 DOI: 10.1021/je3007887.

755

756

757

758

759

\begin{tabular}{|c|c|}
\hline \multicolumn{2}{|c|}{ Addition /Non dissociative attachment } \\
\hline R3 & $\mathrm{H} \cdot+\mathrm{H} \cdot \rightarrow \mathrm{H}_{2}$ \\
\hline R4 & $\cdot \mathrm{OH}+\cdot \mathrm{OH} \rightarrow \mathrm{H}_{2} \mathrm{O}_{2}$ \\
\hline R6 & $\mathrm{e}_{\mathrm{aq}}^{-}+\cdot \mathrm{OH} \rightarrow \mathrm{OH}^{-}$ \\
\hline R7 & $\mathrm{H} \cdot+\cdot \mathrm{OH} \rightarrow \mathrm{H}_{2} \mathrm{O}$ \\
\hline R9 & $\mathrm{e}_{\mathrm{aq}}^{-}+\mathrm{O}_{2} \rightarrow \mathrm{O}_{2}^{-}$ \\
\hline R11 & $\mathrm{e}_{\mathrm{aq}}^{-}+\mathrm{HO}_{2} \rightarrow \mathrm{HO}_{2}^{-}$ \\
\hline R13 & $\mathrm{H} \cdot+\mathrm{O}_{2} \rightarrow \mathrm{HO}_{2}$ \\
\hline R14 & $\mathrm{H} \cdot+\mathrm{HO}_{2} \rightarrow \mathrm{H}_{2} \mathrm{O}_{2}$ \\
\hline R15 & $\mathrm{H}^{\cdot}+\mathrm{O}_{2}^{-} \rightarrow \mathrm{HO}_{2}^{-}$ \\
\hline \multicolumn{2}{|c|}{ Hydrogen abstraction } \\
\hline R2 & $\mathrm{e}_{\mathrm{aq}}^{-}+\mathrm{e}_{\mathrm{aq}}^{-}+\left(2 \mathrm{H}_{2} \mathrm{O}\right) \rightarrow \mathrm{H}_{2}+2 \mathrm{OH}^{-}$ \\
\hline R5 & $\mathrm{e}_{\mathrm{aq}}^{-}+\mathrm{H} \cdot\left(+\mathrm{H}_{2} \mathrm{O}\right) \rightarrow \mathrm{H}_{2}+\mathrm{OH}^{-}$ \\
\hline R10 & $\mathrm{e}_{\mathrm{aq}}^{-}+\mathrm{O}_{2}^{-}\left(+\mathrm{H}_{2} \mathrm{O}\right) \rightarrow \mathrm{H}_{2} \mathrm{O}_{2}+2 \mathrm{OH}^{-}$ \\
\hline R16 & $\cdot \mathrm{OH}+\mathrm{H}_{2} \mathrm{O}_{2} \rightarrow \mathrm{HO}_{2}+\mathrm{H}_{2} \mathrm{O}$ \\
\hline R19 & $\mathrm{HO}_{2}+\mathrm{HO}_{2} \rightarrow \mathrm{H}_{2} \mathrm{O}_{2}+\mathrm{O}_{2}$ \\
\hline R20 & $\mathrm{O}_{2}^{-}+\mathrm{HO}_{2} \rightarrow \mathrm{HO}_{2}^{-}+\mathrm{O}_{2}$ \\
\hline R21 & $\mathrm{O}_{2}^{-}+\mathrm{O}_{2}^{-}+\left(\mathrm{H}^{+}\right) \rightarrow \mathrm{HO}_{2}^{-}+\mathrm{O}_{2}$ \\
\hline \multicolumn{2}{|c|}{ Addition dissociation / Dissociative attachment } \\
\hline R8 & $\mathrm{e}_{\mathrm{aq}}^{-}+\mathrm{H}_{2} \mathrm{O}_{2} \rightarrow \cdot \mathrm{OH}+\mathrm{OH}^{-}$ \\
\hline R12 & $\mathrm{H} \cdot+\mathrm{H}_{2} \mathrm{O}_{2} \rightarrow \cdot \mathrm{OH}+\mathrm{H}_{2} \mathrm{O}$ \\
\hline R14a & $\mathrm{H} \cdot+\mathrm{HO}_{2} \rightarrow 2 \cdot \mathrm{OH}$ \\
\hline R17 & $\cdot \mathrm{OH}+\mathrm{O}_{2}^{-} \rightarrow\left(\mathrm{HO}_{3}^{-}\right) \rightarrow \mathrm{O}_{2}+\mathrm{OH}^{-}$ \\
\hline R18 & $\cdot \mathrm{OH}+\mathrm{HO}_{2} \rightarrow\left(\mathrm{H}_{2} \mathrm{O}_{3}\right) \rightarrow \mathrm{O}_{2}+\mathrm{H}_{2} \mathrm{O}$ \\
\hline \multicolumn{2}{|c|}{ Dissociation } \\
\hline R22 & $\mathrm{H}_{2} \mathrm{O}_{2} \rightarrow 1 / 2 \mathrm{O}_{2}+\mathrm{H}_{2} \mathrm{O}$ \\
\hline R22a & $\mathrm{H}_{2} \mathrm{O}_{2} \rightarrow 2 \cdot \mathrm{OH}$ \\
\hline
\end{tabular}

760 Table 1 The reactions studied in this paper are classified according to their mechanisms. 


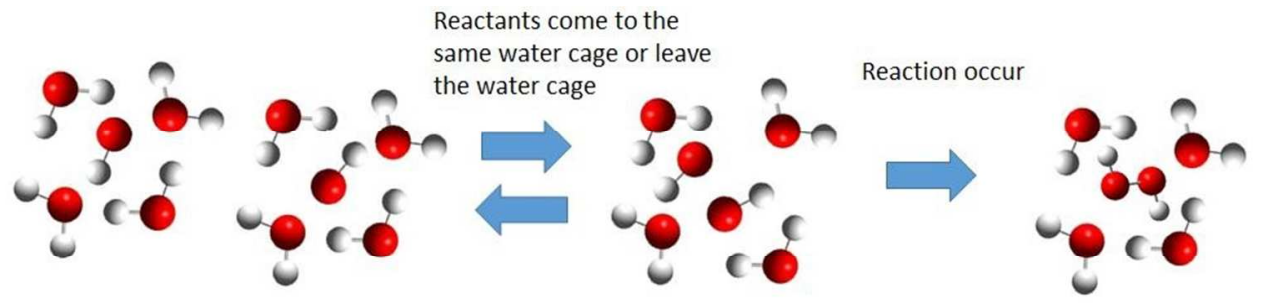

Reactants collide with each other till a reaction occurs

or leave the water cage, two processes are competing
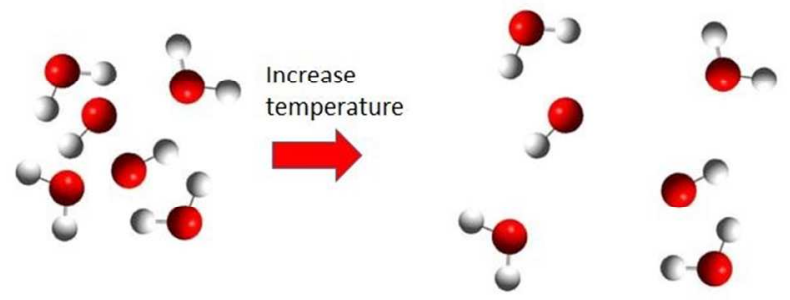

Hydrogen bonds are weakened, reactants leave the water cage much faster, thus the reaction efficiency is lowered

$85 \times 49 \mathrm{~mm}(300 \times 300$ DPI $)$ 